\title{
Avaliação dos impactos ambientais gerados na implantação das pequenas centrais hidrelétricas Canhadão e Tigre no Sudoeste do Paraná, pelo método RIAM
}

\author{
Evaluation of environmental impacts generated in the implementation of \\ the small hydroelectric center Canhadão and Tigre in southeast Paraná by \\ the RIAM method
}

\author{
Julio Caetano Tomazoni'; Karen Merediana Rodrigues de Conto Andretta"
}

\section{RESUMO}

O impacto ambiental está_relacionado à alteração realizada no meio ambiente, seja ela negativa ou positiva, portanto, ao estudá-los avalia-se as consequências de ações, para que possa ser preservada a qualidade do ambiente em todas as fases de desenvolvimento do_empreendimento. O presente artigo tem como objetivo analisar os impactos ambientais ocasionados pela implantação das Pequenas Centrais Hidrelétricas (PCHs) Canhadão e Tigre no Sudoeste do Paraná, através do método da matriz de avaliação de impacto rápido RIAM. Para realizar tal análise, tendo o intuito de tornar o processo o menos subjetivo possível, procurou-se o auxílio de geotecnologias, levantamento de campo e documentos relacionados com as PCHs. Os resultados dessas matrizes permitiram identificar que os impactos negativos significativos foram: a alteração da vazão a jusante em função do período de enchimento do reservatório e / ou desvio permanente do rio, a inundação da vegetação com perda do patrimônio vegetal, o desmatamento do canteiro de obras, locais que são prejudiciais à produção florestal, assoreamento do reservatório, processos de erosão, degradação das áreas utilizadas para a exploração de material de construção e obras de construção temporárias. Os impactos positivos significativos foram: a melhoria da rede rodoviária local e, no contexto atual, as $\mathrm{PCHs}$, são apresentadas como uma das formas mais sustentáveis de produzir energia elétrica, utilizando o potencial hidráulico da região estudada.

Palavras-chave: Avaliação de impacto ambiental; Matriz de avaliação de impacto rápido -RIAM; Pequena central hidrelétrica - PCH

\section{ABSTRACT}

The environmental impact is related to the change made in the environment, whether negative or positive, therefore, by studying them, the consequences of actions are evaluated, so that the quality of the environment can be preserved at all stages of development of the enterprise. This article aims to analyze the environmental impacts caused by the implementation Canhadão and Tigre Small Hydroelectric Plant (SHP) in Southwest Paraná through the rapid impact assessment matrix method - RIAM. In order to perform such analysis, in order to make the process as subjective as possible, we sought the help of geotechnologies, field surveys and documents related to SHPs. The results of these matrices allowed us to identify that the significant negative impacts were: the alteration of the downstream discharge due to the reservoir filling period and / or permanent river diversion, the flooding of vegetation with loss of plant heritage,

'Bacharel e Licenciado em Geografia pela Faculdade de Ciências Humanas de Francisco Beltrão, Mestre, Doutor em Geologia e PósDoutor em Química Inorgânica pela Universidade Federal do Paraná.

"Graduada em Engenharia Ambiental, Mestre em Desenvolvimento Regional pela Universidade Tecnológica Federal do Paraná - Campus Pato Branco. 
deforestation the site of construction sites that are detrimental to forest production, siltation of the reservoir, erosion processes, degradation of the areas used for the exploitation of construction material and temporary construction works. The significant positive impacts were: the improvement of the local road network and, in the current context, the SHPs, are presented as one of the most sustainable ways of producing electric energy, using the hydraulic potential of the studied region.

Keywords: Environmental Impact Assessment; Rapid Impact Assessment Matrix - RIAM; Small Hydroelectric Plant - SHP

\section{INTRODUÇÃO}

O constante aumento populacional e a grande expansão da tecnologia têm como consequência uma urbanização cada vez mais acelerada das cidades, e assim a demanda por energia elétrica está cada vez maior. O Atlas de Energia Elétrica do Brasil (ANEEL, 2008) enfatiza que "além do desenvolvimento econômico, outra variável que determina o consumo de energia é o crescimento da população". Além destes fatores_tem-se os gastos com energia elétrica e o consumismo, utilizados de maneiras e com intensidades variadas entre as diferentes classes sociais.

Tanto nacionalmente quando em âmbito estadual houve um crescimento populacional considerável. No país, segundo o IBGE (2010), a população passou de 183_9_milhões de habitantes do ano de 2007 para uma estimativa de 207,7 milhões de habitantes em 2017 IBGE (2017), o que representa aumento de aproximadamente 13\%. No Estado do Paraná, a população no ano de 2007 era de 10.284 .503 habitantes e a estimativa para 2017 era de 11.320.892 habitantes IBGE (2017), ou seja, um aumento de aproximadamente $10 \%$ de habitantes em 10 anos.

Em relação ao consumo de energia elétrica,_este vem em ritmo acelerado considerando que no ano de 2003 houve um crescimento de 6,5\% em relação ao ano anterior, em 2004 um aumento de 5,2\%, em 2005 mais 4,2\%, em 2006 teve acréscimo de 3,9\% e em 2007 de 5,7\% (ANEEL, 2008).

Nesse sentido, para obter um equilíbrio entre demanda e oferta, deve-se aumentar a potência dos modelos já existentes de obtenção de energia elétrica, ou analisar novas alternativas para suprir tal demanda. Além disso, cabe a cada indivíduo racionalizar o máximo possível o uso de energia elétrica em suas atividades diárias. 
Independentemente do empreendimento, ao produzir energia, geram-se impactos ambientais dos mais variados níveis de degradação, e por isso é de suma importância que ao planejar a geração de energia elétrica, sejam levados em consideração não somente seus benefícios econômicos, mas também o que esta geração trará de consequências para o meio ambiente. Principalmente em sua fase de implantação, pois, para determinados empreendimentos, como é o caso dos projetos de infraestrutura, essa etapa pode acarretar os impactos mais importantes (SÁNCHEZ, 2013, p. 206). Salienta-se ainda, a importância de avaliar tanto os aspectos ambientais positivos quanto os negativos para melhor esclarecimento do quão eficiente e impactante o mesmo será ao meio ambiente.

Segundo o Banco de Informação e Geração - BIG, ANEEL (2017), dos empreendimentos em operação no Brasil, a maior porcentagem de potência instalada é derivada de usinas hidrelétricas, considerando que além das unidades hidrelétricas de energia - UHEs, que se destacam, ainda tem as pequenas centrais hidrelétricas PCHs e as centrais geradoras hidrelétricas - CGHs que estão enquadradas como hidrelétricas. Ainda segundo o BIG (ANEEL, 2017), considerando as PCHs em operação e em construção no Estado do Paraná, no mês de novembro de 2017 havia 33 usinas. A partir disso optou-se por estudar duas $\mathrm{PCHs}$.

Então, o recorte feito para o presente estudo foi geográfico, considerando a região Sudoeste do Paraná, e pelo tempo útil disponível para a realização do estudo, delimitando a potência instalada, neste sentido procurou-se avaliar usina do tipo $\mathrm{PCH}$, ou seja, com potência entre 1.000 e 30.000 kW segundo o atlas da ANEEL (2008) e ELETROBRÁS (2000).

Para identificar ou analisar os impactos existem múltiplas formas, mas Sánchez (2013), deixa claro que tais instrumentos ajudam e facilitam o trabalho, porém não se tratam de "pacotes" acabados. Para ljäs et al. (2009) a Avaliação de Impacto Ambiental - AlA procura determinar os principais impactos do projeto, podendo assim planejar medidas adequadas para mitigar os mesmos. Apesar da importância na 
gestão ambiental, a AIA é considerada um dos elementos mais difíceis e menos compreendidos do processo, isso se deve à sua natureza subjetiva (Duinkerand Beanlands, 1986 e Lawrence, 2007 apud IJÄS et al., 2009).

Dentre as várias formas de se realizar uma AIA existem as matrizes e como Martins e Neto (2015), descrevem, "existem métodos de avaliação de impactos ambientais mais rápidos e menos onerosos financeiramente, como é o caso do The Rapid Impact Assessment Matrix (RIAM) (MARTINS e NETO, 2015, p.43). Tal método foi desenvolvido por Cristopher_Pastakia (Pastakia, 1998, Pastakia e Jensen, 1998) no final da década de 1990 e, até então, foi testado em várias situações de avaliação e estudos de caso (por exemplo, Al Malek e Mohamed, 2005; El_Naqa 2005, Haie, 2006; Pastakia e Jensen, 1998) (IJÄS et al.,2009, p.82-83).

Autores como ljäset al. (2009) citam o método RIAM para ser utilizado com o objetivo de transformar tal natureza subjetiva em algo mais transparente ao processo de avaliação. Onde, diferentes impactos e sua significância podem ser avaliadas usando critérios comumente definidos, cada um com suas próprias escalas ordinais. Assim, pode-se facilmente comparar e revisar os resultados.

Com isto, o objetivo foi analisar os impactos gerados pelas Pequenas Centrais Hidrelétricas Canhadão e Tigre, estando respectivamente, uma em sua fase inicial e a outra em sua fase final de implantação.

\section{MATERIAIS E MÉTODOS}

No período de um ano e meio foram estudadas duas PCHs do município de Mangueirinha, no Sudoeste do Paraná. Ambas as PCHs estudadas localizam-se na bacia hidrográfica do Rio Iguaçu. Sendo que a PCH Canhadão, localiza-se na subbacia do Rio Covó, e a PCH Tigre situa-se na sub-bacia do Rio Marrecas como podese ver a localização através da Figura 1. 
Figura 1 - Localização da sub-bacia hidrográfica do Rio Covó e da Bacia Hidrográfica do Rio Marrecas

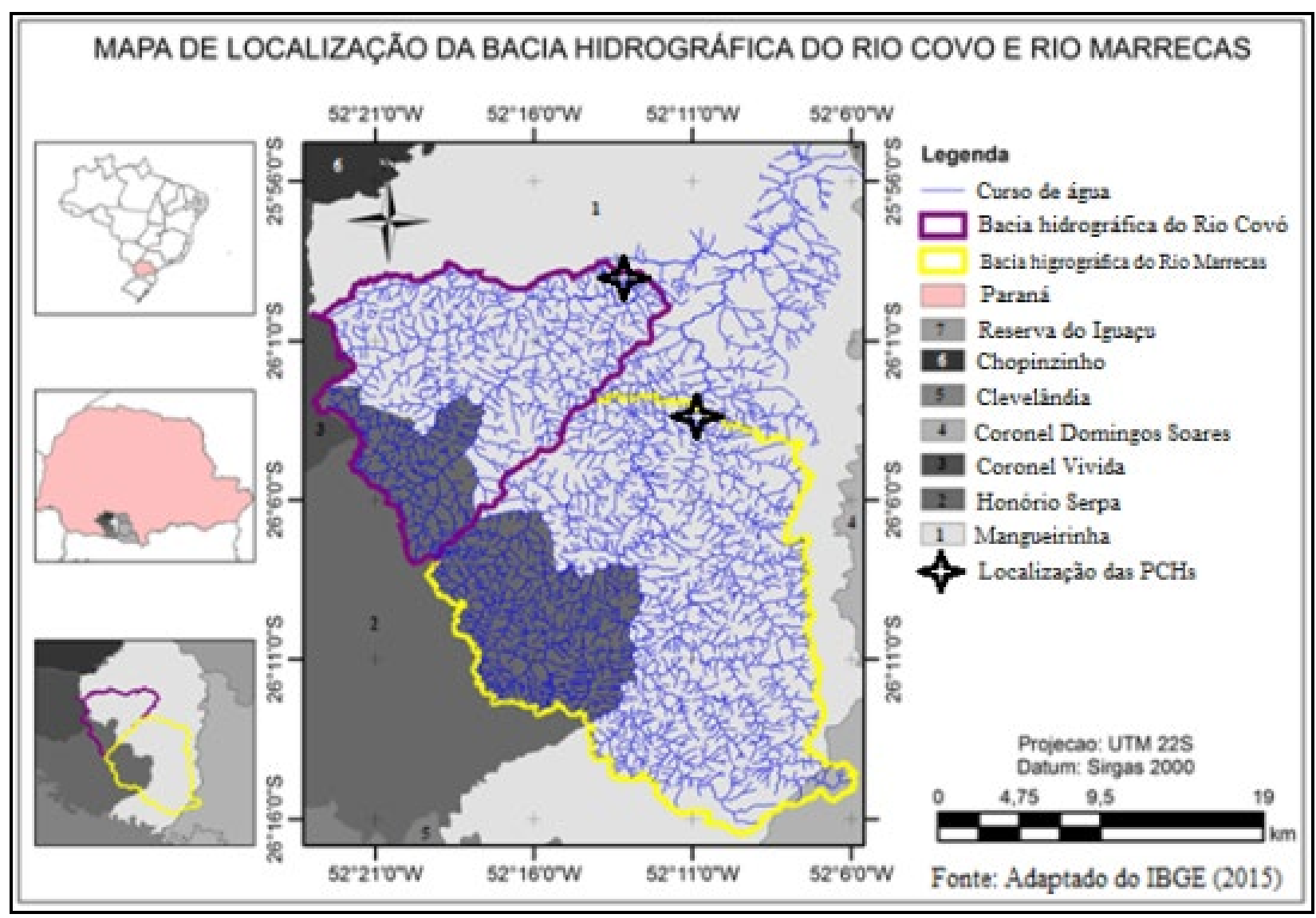

Fonte: Autores, 2018.

Para a análise dos impactos utilizou-se do método Rapid Impact Assessment Matrix - RIAM, ou, Matriz de Avaliação de Impacto Rápido, a escolha foi pelo fato de ser uma matriz de aplicação rápida, pois procurou-se priorizar impactos e parâmetros que poderiam ser avaliados, destacando o tempo útil para a realização do estudo, e também por não haver uma equipe multidisciplinar para auxiliar na construção de uma matriz detalhada de impactos.

Para este estudo procurou-se utilizar de análise de documentos como o relatório ambiental simplificado - RAS, o plano ambiental de conservação e uso do entorno do reservatório - PACUERA, o programa ambiental de geração de mão de obra local; observações de campo, com registros fotográficos; o geoprocessamento, na confecção de mapas e estudos já realizados juntamente, com livros da área para a 
base teórica e direcionamento a respeito dos impactos. Métodos estes que vieram a auxiliar no preenchimento, de forma menos subjetiva possível, da matriz.

A descrição dos meios a serem disposto nas matrizes, Pastakia e Jensen (1998) utilizam a seguinte divisão com sua respectiva denominação: Físico/Químico (PC); Biológico / Ecológico (BE); Sociológico / Cultural (SC); Econômico / Operacional (EO).

Após montada as matrizes o preenchimento destas seguiu levando-se em consideração alguns critérios e pontuações descritos por (PASTAKIA e JENSEN, 1998). Tais autores explicam que "os impactos do projeto são avaliados em relação aos componentes ambientais, e para cada componente é determinada uma pontuação (usando os critérios definidos), que fornece uma medida do impacto esperado do componente" (PASTAKIA e JENSEN, 1998, p. 464). Preliminarmente os autores descrevem, que deve-se considerar que os critérios de avaliação se dividem em dois grupos, sendo eles:

Critérios que são importantes para a condição, que individualmente pode alterar a pontuação;

Critérios que são de valor para a situação, mas não devem ser individualmente capazes de alterar a contagem obtida.

O valor atribuído a cada um desses grupos de critérios é determinado pelo uso de fórmulas simples, as quais permitem que as pontuações para os componentes individuais sejam determinadas de forma já definida.

O sistema de pontuação requer uma simples multiplicação das pontuações atribuídas a cada um dos critérios no grupo (A). O uso do multiplicador para o grupo (A) é importante, pois assegura imediatamente que o peso de cada pontuação seja expresso, enquanto que a soma simples de pontuação pode fornecer resultados idênticos para diferentes condições. As pontuações para o grupo de critérios de valor (B) são adicionadas em conjunto para fornecer uma única soma. Isso garante que as contagens de valores individuais não possam influenciar a pontuação geral, mas que a importância coletiva de todo o grupo de valores (B) seja totalmente levada em consideração. A soma das pontuações do grupo (B) é então multiplicada pelo 
resultado das pontuações do grupo (A) para fornecer uma pontuação de avaliação final (ES) para a condição. O processo pode ser expresso pelas seguintes fórmulas:

$(\mathrm{A} 1) \times(\mathrm{A} 2)=\mathrm{AT}$

$(B 1)+(B 2)+(B 3)=B T$

$(\mathrm{AT}) \times(\mathrm{BT})=\mathrm{ES}$

Onde:

·(A1) (A2) são pontuações de critérios individuais para o grupo (A);

•(B1) (B2) (B3) são as pontuações de critérios individuais para o grupo (B);

- AT é o resultado da multiplicação de todos as pontuações (A);

- BT é o resultado do somatório de todas as pontuações (B); e

- ES é a contagem ambiental para a condição.

A avaliação de cada componente segue a descrição do Quadro 1.

\section{Quadro 1 - Critérios de avaliação}

\begin{tabular}{|c|c|c|}
\hline Critério & Escala & Descrição \\
\hline \multirow{3}{*}{ A1: Importância da condição } & 4 & Importante para interesses nacionais/internacionais \\
& 3 & Importante para interesses regional/nacional \\
& 2 & local \\
& 1 & Importante para áreas imediatamente fora da condição \\
& +3 & Sem importância \\
\hline \multirow{3}{*}{ A2: Magnitude da } & +2 & Grande benefício positivo \\
mudança/efeito & +1 & Melhoria significativa no status quo \\
& 0 & Sem mudança \\
& -1 & Mudança negativa para o status quo \\
& -2 & Desvantagem ou alteração negativa significativa \\
& -3 & Mudança principal \\
\hline B1: Permanência & 1 & Sem alteração/não aplicável \\
& 2 & Temporário \\
& 3 & Permanente \\
\hline \multirow{3}{*}{ B2: Reversibilidade } & 1 & Sem alteração/não aplicável \\
& 2 & Irreversível \\
\hline B3: Cumulativo & 3 & Sem alteração/não aplicável \\
& 1 & Não cumulativo / único \\
& 3 & Cumulativo / sinérgico \\
\hline
\end{tabular}

Fonte: Pastakia e Jensen (1998) 
Após preencher a matriz, considerando os passos apresentados, obtém-se de maneira resumida em qual banda de alcance um impacto analisado se enquadra, podendo assim dizer se o mesmo é positivo ou negativo e ainda, dependendo da pontuação, diferenciar entre uma alteração mais ou menos significativa para o meio.

Para auxiliar no preenchimento da matriz, utilizou-se de geoprocessamento para a confecção de mapas de uso do solo. Sendo que foram utilizadas imagens do satélite Landsat 8 e o software trabalhado foi o Spring 5.4.3.

Foram confeccionados três mapas para cada $\mathrm{PCH}$, em estudo, procurando abranger o antes, durante e depois da construção das PCHs. Para isto, baseou-se nos anos das licenças dos empreendimentos, sendo o primeiro mapa do ano de 2013 que foi o ano em que as duas PCHs obtiveram a licença prévia. Para o segundo mapa baseou-se no ano de 2015, que fica entre a licença de instalação (2014 para ambas as PCHs) e de operação (2016 para o caso da PCH Tigre e 2017 para a PCH Canhadão), e para o terceiro mapa, utilizou-se o ano de 2017, ano em que a pesquisa estava sendo realizada e que a $\mathrm{PCH}$ Canhadão obteve a licença de operação.

Quadro 2 - Conversão das Pontuações Ambientais para Bandas de alcance.

\begin{tabular}{|c|c|c|}
\hline Pontuação ambiental & Bandas de alcance & Descrição das Bandas de alcance \\
\hline+72 até +108 & $+\mathrm{E}$ & Impactos extremamente positivos \\
+36 até +71 & $+\mathrm{D}$ & Impactos significativamente positivos \\
+19 até +35 & $+\mathrm{C}$ & Impactos moderadamente positivos \\
+10 até +18 & $+\mathrm{B}$ & Impactos positivos \\
+1 até +9 & $+\mathrm{A}$ & Impactos ligeiramente positivos \\
0 & $\mathrm{~N}$ & Sem alteração/não aplicável \\
-1 até -9 & $-\mathrm{A}$ & Impactos ligeiramente negativos \\
-10 até -18 & $-\mathrm{B}$ & Impactos negativos \\
-19 até -35 & $-\mathrm{C}$ & Impactos moderadamente negativos \\
-36 t até $0-71$ & $-\mathrm{D}$ & Impactos significativamente negativos \\
-72 até -108 & $-\mathrm{E}$ & Impactos extremamente negativos \\
\hline
\end{tabular}

Fonte: Pastakia e Jensen (1998). 


\section{RESULTADOS E DISCUSSÃO}

Com os levantamentos realizados afim de conhecer melhor a região em estudo diagnosticou-se que tanto para a sub-bacia do Rio Covó quanto na bacia do Rio Marrecas houve predominância de uma declividade considerada entre suavemente ondulada e ondulada, e a predominância do solo encontrado foram dos_latossolos, tendo também, em menores quantidades, a ocorrência de cambissolos, neossolos e nitossolos. Os latossolos são solos profundos, bem drenados e que tem por característica aparecer em relevos suaves, além disto, são estáveis para suportar construções como no caso das PCHs.

Através do método RIAM, analisaram-se os impactos gerados pela implantação das PCHs Canhadão e Tigre. Com os resultados, obteve-se uma divisão destes impactos dispostos da seguinte forma: tanto para os impactos considerados negativos quanto para os impactos considerados como positivos, verificou-se três escalas de ponderação, sendo elas em ordem decrescente: impactos significativamente negativos (-D), impactos moderadamente negativos (-C) e impactos ligeiramente negativos (-A).

A matriz representando os impactos gerados pela PCH Canhadão ao meio ambiente está apresentada na Tabela 1.

Referente aos impactos significativamente negativos foram verificados a alteração da descarga a jusante em função do período de enchimento do reservatório e/ou do desvio permanente do rio, o assoreamento do reservatório, os processos erosivos, a degradação das áreas utilizadas pela exploração de material de construção e pelas obras temporárias de construção civil (corte e movimentação de solo e rocha), a inundação da vegetação com perda de patrimônio vegetal e desmatamento nos locais das obras.

Sobre a alteração da descarga a jusante em função do período de enchimento do reservatório e/ou do desvio permanente do rio, este_aspecto demonstrou-se como uma alteração que para o momento a mesma foi significativa para aquele ambiente, mesmo que mantendo a vazão sanitária, como é destacado por (PCH CANHADÃO, 2017). Nas Figuras 2, 3 e 4 procurou-se demonstrar como era a vazão do rio antes, durante e após o enchimento do reservatório, respectivamente. 
Tabela 1 - Matriz de avaliação de impacto rápido da PCH Canhadão.

\begin{tabular}{|c|c|c|c|c|c|c|c|c|c|c|}
\hline & COMPONENTES & $\mathrm{A} 1$ & A2 & AT & B1 & B2 & B3 & BT & ES & $\mathrm{RB}$ \\
\hline PC1 & $\begin{array}{c}\text { Alteração da descarga a jusante pelo } \\
\text { enchimento do reservatório e do desvio } \\
\text { do rio }\end{array}$ & 3 & -2 & -6 & 3 & 2 & 2 & 7 & -42 & $-D$ \\
\hline PC2 & Assoreamento do reservatório & 3 & -2 & -6 & 2 & 2 & 3 & 7 & -42 & $-D$ \\
\hline PC3 & Qualidade da água & 2 & -2 & -4 & 2 & 2 & 3 & 8 & -32 & $-C$ \\
\hline PC4 & Processos erosivos & 3 & -2 & -6 & 2 & 2 & 3 & 7 & -42 & $-D$ \\
\hline PC5 & $\begin{array}{l}\text { Degradação das áreas utilizadas pela } \\
\text { exploração de material de construção }\end{array}$ & 2 & -3 & -6 & 3 & 3 & 2 & 8 & -48 & $-D$ \\
\hline PC6 & Interferência no uso do solo & 1 & -1 & -1 & 3 & 3 & 2 & 2 & -8 & $-A$ \\
\hline PC7 & $\begin{array}{c}\text { Alteração do ambiente de lótico para } \\
\text { lêntico }\end{array}$ & 2 & -2 & -4 & 3 & 3 & 2 & 8 & -32 & $-C$ \\
\hline PC8 & Alteração do habitat & 3 & -1 & -3 & 3 & 2 & 2 & 7 & -21 & $-C$ \\
\hline PC9 & Resíduos sólidos & 2 & -1 & -2 & 2 & 1 & 1 & 4 & -8 & $-A$ \\
\hline PC10 & Esgotamento sanitário & 2 & -1 & -2 & 2 & 1 & 1 & 4 & -8 & $-A$ \\
\hline PC11 & Área de bota-fora & 1 & -1 & -1 & 3 & 3 & 2 & 8 & -8 & $-A$ \\
\hline PC12 & $\begin{array}{l}\text { Ruídos de explosões e máquinas + } \\
\text { emissões }\end{array}$ & 2 & -2 & -4 & 2 & 2 & 3 & 7 & -28 & $-C$ \\
\hline PC13 & Rede viária & 2 & 3 & 6 & 3 & 3 & 3 & 9 & 54 & $\mathrm{D}$ \\
\hline PC14 & $\begin{array}{l}\text { Alojamentos/instalações durante as } \\
\text { obras }\end{array}$ & 1 & -1 & -1 & 2 & 2 & 1 & 5 & -5 & $-A$ \\
\hline PC15 & Proliferação e vetores & 1 & -1 & -1 & 2 & 2 & 3 & 7 & -7 & $-A$ \\
\hline PC16 & Alteração na paisagem como um todo & 3 & -1 & -3 & 3 & 3 & 3 & 9 & -27 & $-\mathrm{C}$ \\
\hline BE1 & $\begin{array}{c}\text { Inundação da vegetação com perda de } \\
\text { patrimônio vegetal }\end{array}$ & 3 & -2 & -6 & 3 & 2 & 3 & 8 & -48 & $-D$ \\
\hline BE2 & $\begin{array}{c}\text { Perda de habitats naturais e da } \\
\text { disponibilidade alimentar para a fauna } \\
\text { terrestre }\end{array}$ & 2 & -2 & -4 & 2 & 2 & 3 & 7 & -28 & $-\mathrm{C}$ \\
\hline BE3 & Diminuição da pesca & 2 & -1 & -2 & 1 & 2 & 1 & 4 & -8 & $-A$ \\
\hline BE4 & Desmatamento nos locais das obras & 3 & -2 & -6 & 3 & 2 & 3 & 8 & -48 & $-D$ \\
\hline BE5 & $\begin{array}{c}\text { Ameaças de atropelamento de animais } \\
\text { silvestres }\end{array}$ & 3 & -1 & -3 & 3 & 3 & 2 & 8 & -24 & $-C$ \\
\hline SC1 & Interferência em terras vizinhas & 2 & -1 & -2 & 1 & 1 & 1 & 3 & -6 & $-A$ \\
\hline SC2 & Interferência no potencial turístico & 3 & -1 & -3 & 1 & 1 & 1 & 3 & -9 & $-A$ \\
\hline EO1 & Oportunidade de emprego & 3 & 1 & 3 & 2 & 2 & 3 & 7 & 21 & $\mathrm{C}$ \\
\hline $\mathrm{EO} 2$ & Novas oportunidades para a economia & 3 & 1 & 3 & 3 & 2 & 3 & 8 & 24 & $\mathrm{C}$ \\
\hline $\mathrm{EO} 3$ & Maior oferta de energia & 3 & 1 & 3 & 3 & 3 & 3 & 3 & 9 & A \\
\hline EO4 & Perda de área de pastagem & 1 & -1 & -1 & 3 & 3 & 3 & 9 & -9 & $-A$ \\
\hline EO5 & $\begin{array}{c}\text { Aumento de arrecadação tributária } \\
\text { municipal }\end{array}$ & 2 & 2 & 4 & 3 & 2 & 3 & 8 & 32 & $\mathrm{C}$ \\
\hline EO6 & Riscos de acidentes de trabalho & 2 & -1 & -2 & 2 & 1 & 1 & 4 & -8 & $-A$ \\
\hline EO7 & Indenização e regularizações & 2 & 2 & 4 & 3 & 3 & 2 & 8 & 32 & C \\
\hline EO8 & $\begin{array}{l}\text { Desmobilização de mão de obra } \\
\text { contratada ao final das obras }\end{array}$ & 3 & -2 & -6 & 1 & 2 & 1 & 4 & -24 & $-C$ \\
\hline
\end{tabular}

Fonte: Autores, 2018. 
Figura 1 - Trecho do Rio Covó antes da implantação da barragem.

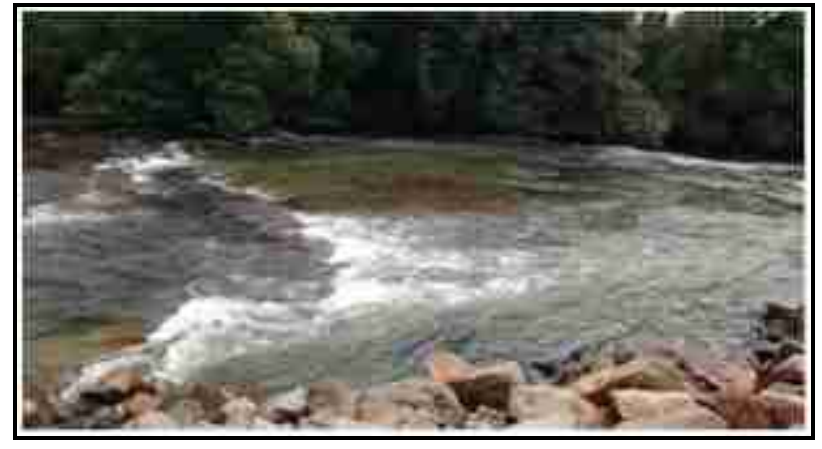

Fonte: Autores, 2018.

Figura 2 - Trecho do Rio Covó a jusante do barramento, no dia do enchimento do reservatório.

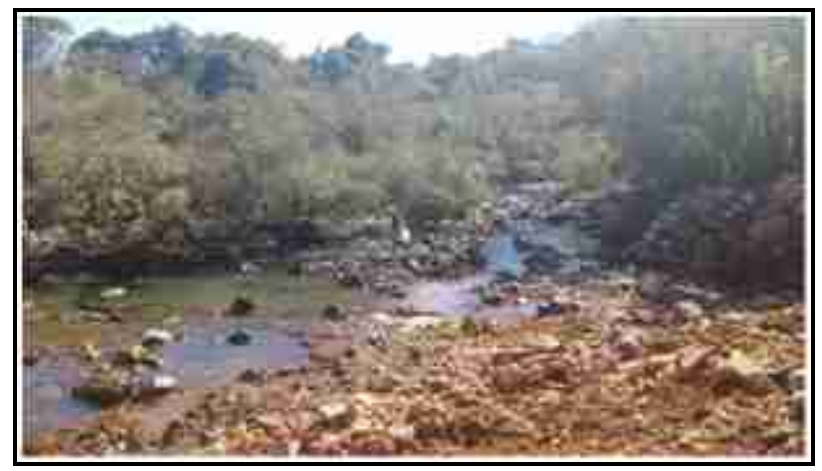

Fonte: Autores, 2018.

Figura 4 - Trecho do Rio Covó após o enchimento do reservatório.

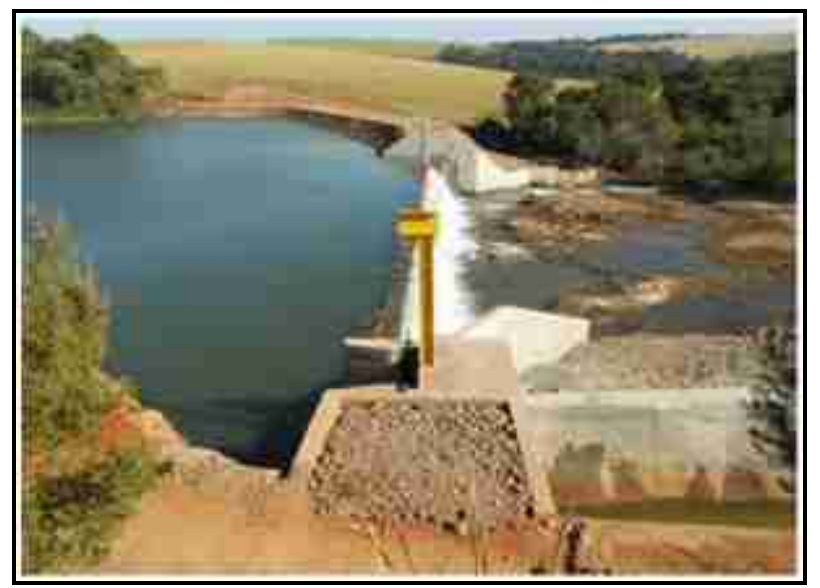

Fonte: Autores, 2018. 
Quanto ao assoreamento do reservatório, aos processos erosivos e a degradação das áreas utilizadas pela exploração de material de construção e pelas obras temporárias de construção civil (corte e movimentação de solo e rocha) procurou-se demonstrar, através de imagens, alguns dos locais onde houve o revolvimento do solo,_sejam pelas supressões da vegetação ou pela necessidade da realização de cortes para aberturas de vias de acesso e obras civis, e também onde houve a abertura da rocha. Segundo a FBF Construtora (2017) a escavação em solo foi de $155.022,65 \mathrm{~m}^{3}$ e a escavação em rocha a céu aberto foi de $41.274,85 \mathrm{~m}^{3}$.

Com as Figuras 5 e 6 observa-se como era o ambiente no local do barramento e desvio do rio durante a fase inicial e a fase final da implantação da PCH Canhadão, e a Figura 7, traz este mesmo local já com o futuro reservatório a ser preenchido, ou seja, procurou-se demonstrar uma sequência de imagens buscando a compreensão das alterações realizadas.

Com a Figura 5 pode-se diagnosticar a existência de uma faixa de mata ciliar, a qual foi em parte suprimida para a construção da barragem e posterior enchimento do reservatório, restando apenas um fragmento desta mata - Figura 6. Essa retirada de mata ciliar traz outros impactos como consequência, por exemplo, a erosão desta encosta e o assoreamento neste trecho do rio. Pelas mesmas figuras, logo na sequência das faixas de uso do solo, além do rio e_da mata ciliar, percebe-se a presença de atividade agrícola, deixando o rio, devido a supressão da vegetação ciliar, ainda mais exposto e susceptível as práticas por esta atividade. Além disto, através destas figuras percebe-se o desvio realizado no rio, o revolvimento e a compactação do solo, que são consequências das construções.

Nas Figuras 7 e 8 além do corte no solo realizado para a implantação do canal, ainda demonstra aspectos do revolvimento do solo, que tem como consequência a erosão neste local, o que acarreta no assoreamento do rio a jusante deste ponto. 
Figura 3 - Fase inicial da implantação da PCH, demonstrando a construção do desvio com a escadaria para deslocamento da fauna aquática.

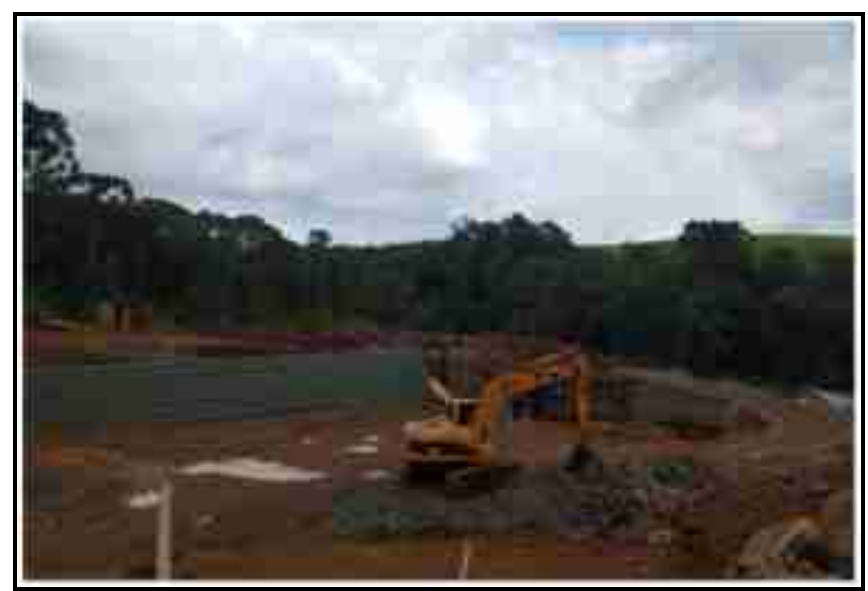

Fonte: Autores, 2018.

Figura 4 - Fase final da implantação do barramento e o desvio.

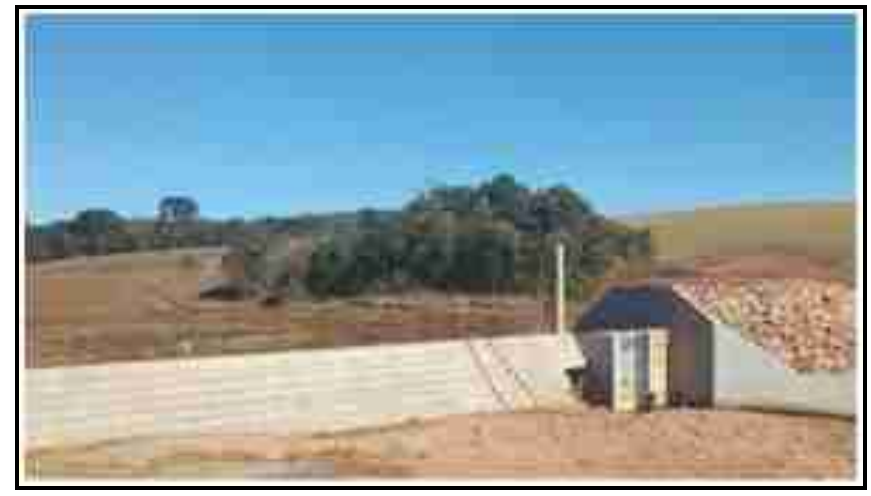

Fonte: Autores, 2018.

Figura 7 - Vista do corte no solo na margem direita do futuro reservatório.

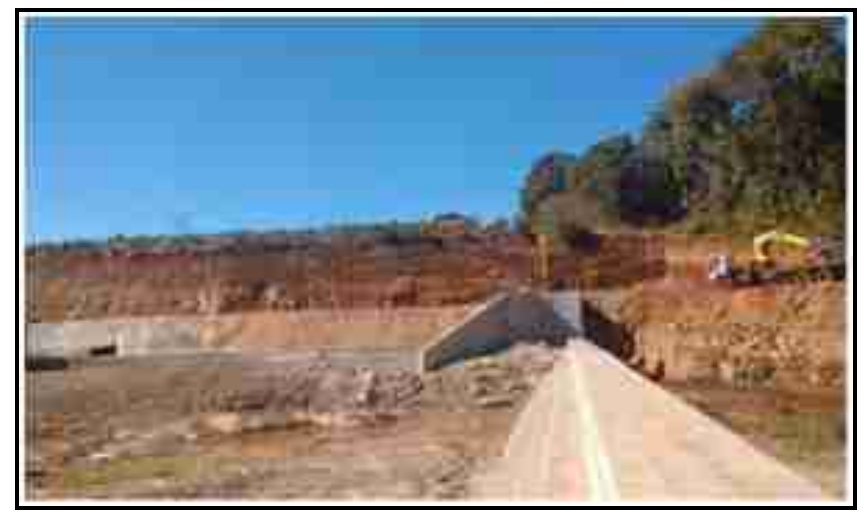

Fonte: Autores, 2018. 
Figura 8 - Local do futuro reservatório.

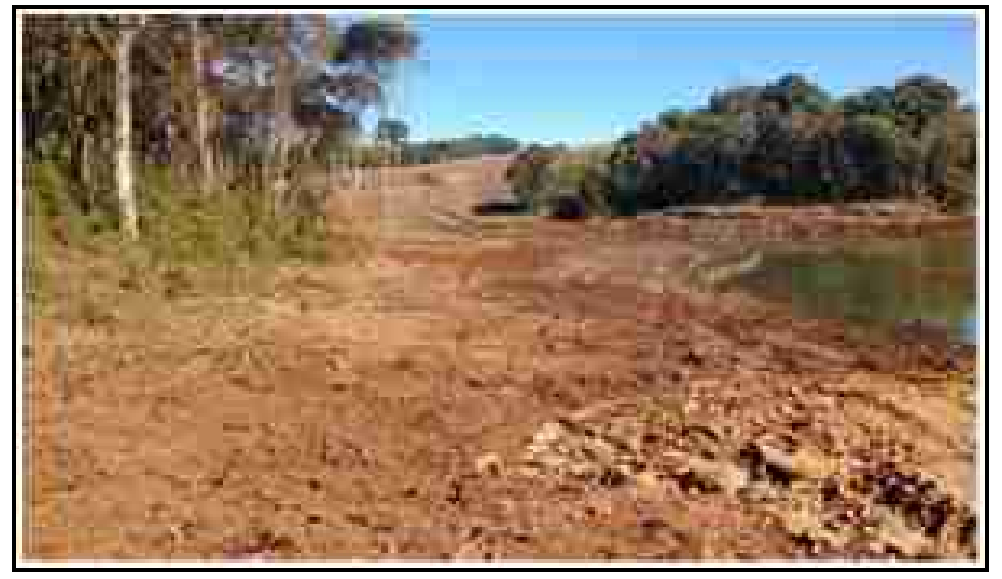

Fonte: Autores, 2018.

O andamento das obras do canal é demonstrado nas Figuras 9, 10 e 11. Pela característica do canal da PCH Canhadão ter um longo trecho, torna-se necessária a abertura de um espaço consideravelmente grande para a implantação do mesmo, com isso a necessidade de alteração nestes locais torna-se ainda mais significativa. Destaca-se que no decorrer da implantação do trecho de canal foram necessárias aberturas para a vala tanto em solo quanto em rocha. Além disto, em alguns locais diagnosticou-se a precisão da prática de desmatamento.

Ao final das obras referentes ao canal, o mesmo foi impermeabilizado e preenchido como pode-se notar pela Figura 11, que mostra parte do trecho deste canal.

A Figura 12 traz o antes e depois de outra parte constituinte da $\mathrm{PCH}$, o conduto forçado, demonstrando o decaimento necessário até a casa de força.

Figura 9 - Fase inicial da construção do canal.

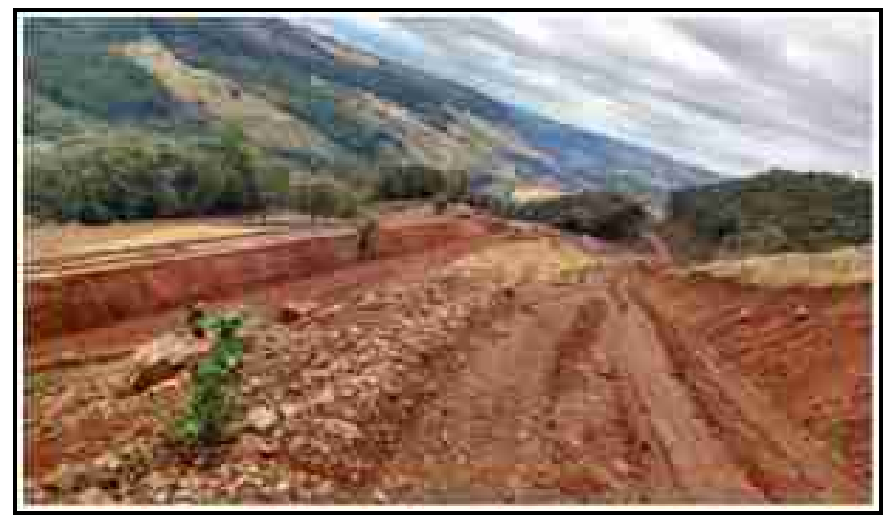

Fonte: Autores, 2018. 
Figura 10 - Trechos da implantação do canal com abertura em rocha.

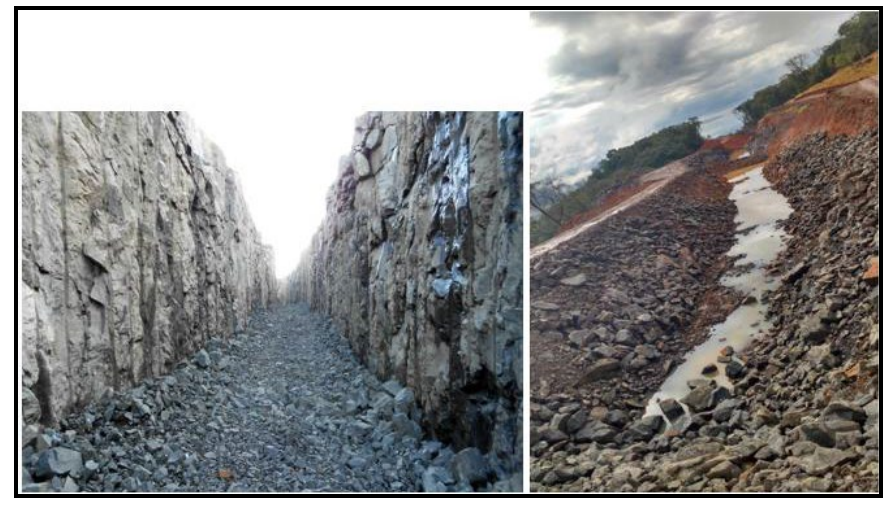

Fonte: Autores, 2018.

Figura 11 - Fase final da implantação do canal, com o mesmo já impermeabilizado e preenchido

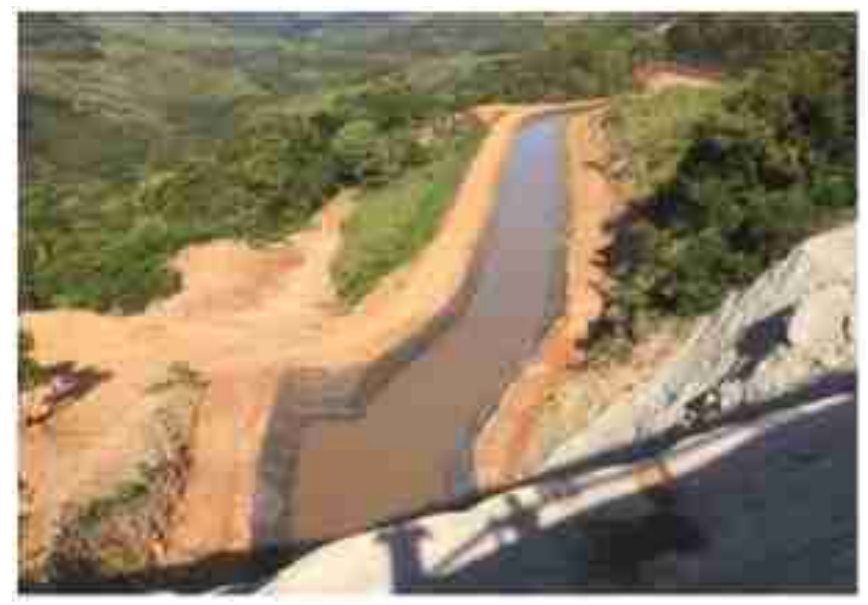

Fonte: Autores, 2018.

Figura 12 - Implantação do conduto forçado.

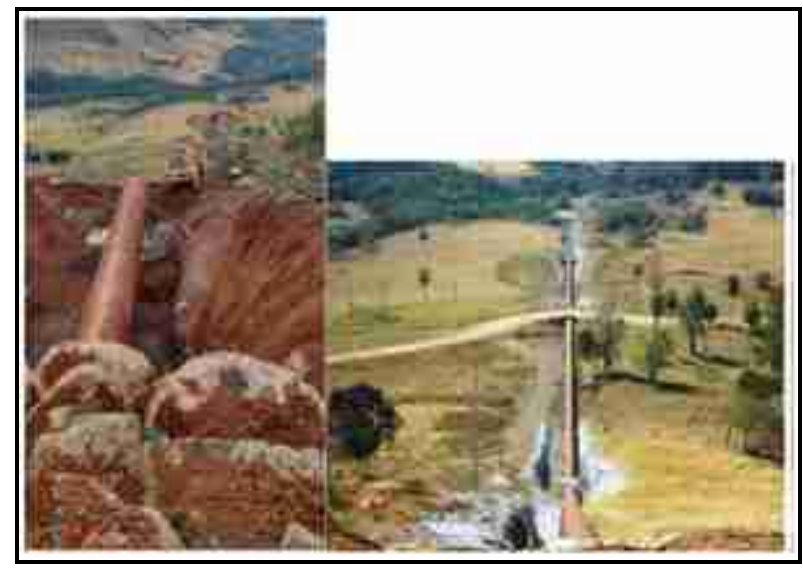

Fonte: Autores, 2018. 
A Figura 13 refere-se a uma imagem do trecho do rio logo após a casa de força, nota-se o corte realizado no solo para abertura da estrada e para a construção da própria casa de força, com consequência de processos erosivos neste local, e da mesma forma que já comentado para as outras localidades, processo este que promove o assoreamento do rio. Como alteração, também percebe-se a abertura na vegetação ciliar na margem direita do rio.

Referente aos impactos ocasionados pela inundação da vegetação, com perda de patrimônio vegetal e desmatamento nos locais das obras, ambos geram prejuízos no aspecto florestal.

Pode-se verificar através de algumas imagens anteriormente apresentadas, que o desmatamento foi realizado em diferentes localidades e com intensidades diferenciadas, para a construção do barramento, do canal, da casa de força e para preparar o terreno para o enchimento do reservatório.

Como impactos moderadamente negativos obteve-se a qualidade da água, a alteração do ambiente lótico para lêntico, a alteração do habitat, a perda de habitats naturais e da disponibilidade alimentar para a fauna terrestre, ameaça de atropelamento de animais silvestres, os ruídos de explosões e máquinas e as emissões atmosféricas geradas, a alteração na paisagem como um todo e a desmobilização de mão de obra contratada ao final das obras.

Sobre a qualidade da água, no trecho do Rio Covó onde localiza-se a PCH Canhadão,_a mesma é considerada ruim de acordo com a metodologia Índice de Qualidade da água (IQA). E os resultados encontrados por (FORTE, 2016), apontam valores acima dos valores máximos determinados pelo_Conselho Nacional do Meio Ambiente - CONAMA (2005) para as análises de coliformes termotolerantes e fenol. Para FORTE (2016) o principal fator desta classificação é a falta de saneamento no distrito de Covó e o possível despejo irregular de efluente industrial, oficina mecânica, posto de combustível, ou outra fonte.

Houve alteração do ambiente de lótico para lêntico, principalmente a montante do barramento, mas com alterações também a jusante em alguns períodos como no momento do enchimento do reservatório.

A Figura 14 traz um registro fotográfico da fase inicial do enchimento do reservatório, e quando comparada a sua vazão com a Figura 2, pode-se perceber o 
impacto desta transição de ambientes com vazão antes mais fluente e durante o enchimento mais lêntica.

Da mesma forma acrescenta-se a este diagnóstico a Figura 4, que mostra o andamento do rio após o enchimento do reservatório, o que enfatiza-se a frase descrita acima, de que esta alteração ficará principalmente marcada a montante do barramento, mas que_também será sentida a jusante, uma vez que, até o rio se encontrar em sua calha natural novamente, verifica-se que logo após o desvio, justamente por essa alteração, o escoar da água_está mais "espalhado", o que leva-se a perceber que naquele local da nova calha do rio, a mesma será acrescida em sua largura. Alterações estas que com o passar do tempo, e com a adaptação e regeneração do ambiente se tornaram "normal" considerando-se o espaço/tempo futuro, masque para chegar a esta fase, sofreram alterações.

Figura 13 - Trecho do Rio Covó próximo à casa de força da PCH Canhadão.

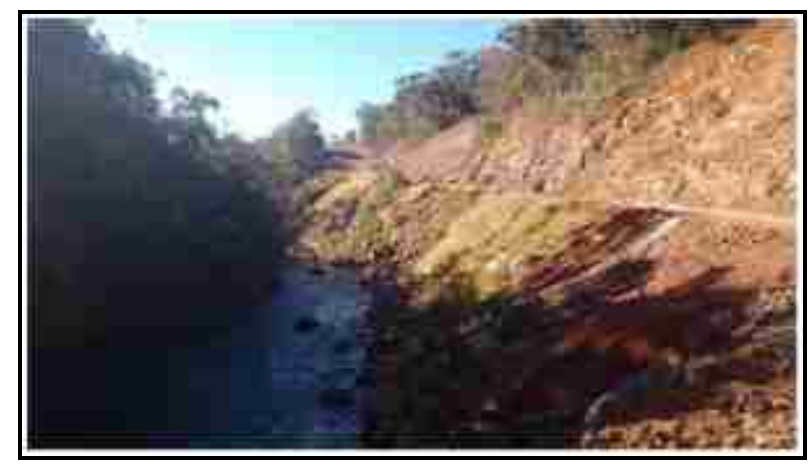

Fonte: Autores, 2018.

Figura 14 - Montante do barramento no início do enchimento do reservatório da PCH no Rio Covó.

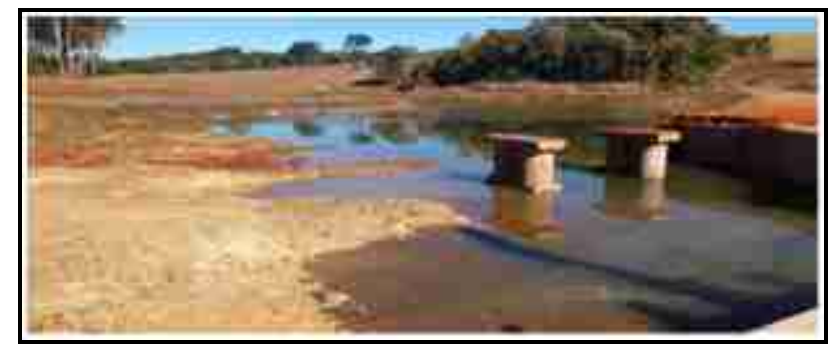

Fonte: Autores, 2018. 
Referente a alteração do habitat, com consequente perda de habitats naturais e da disponibilidade alimentar para a fauna terrestre de animais como, macacos, tatu, veado, capivara, cotia, entre outros e ameaça de atropelamento de animais silvestres são reflexos de alterações como o desmatamento (por isso impacto significativamente negativo).

Na sequência, os ruídos de explosões e máquinas e as emissões atmosféricas geradas. Quando geram-se ruídos sejam de explosões ou de máquinas além das emissões atmosféricas ocasionadas, tem-se a problemática do estresse da fauna local, que juntamente com as alterações do habitat de determinada fauna estes animais tendem a fugir/dispersar-se ou dependendo da situação procurar outro local para sua sobrevivência, neste caminho percorrido os riscos de atropelamentos de animais silvestres são intensificados, principalmente se tem ruas, rodovias próximo destes locais.

Como um impacto acarreta outro, com a junção de todas as alterações citadas a acima tem-se a alteração na paisagem como um todo, que é reflexo da implantação da obra em geral, mesmo que dentro de uma paisagem já antropizada, como verificado nos mapeamentos_realizados nesta pesquisa, e diagnosticados também pela Figura 15, tem-se uma modificação e esta é percebida como inclusa no uso e ocupação da porção de solo em estudo.

Figura 5 - Vista da construção da PCH na paisagem, destacando os usos do solo próximos.

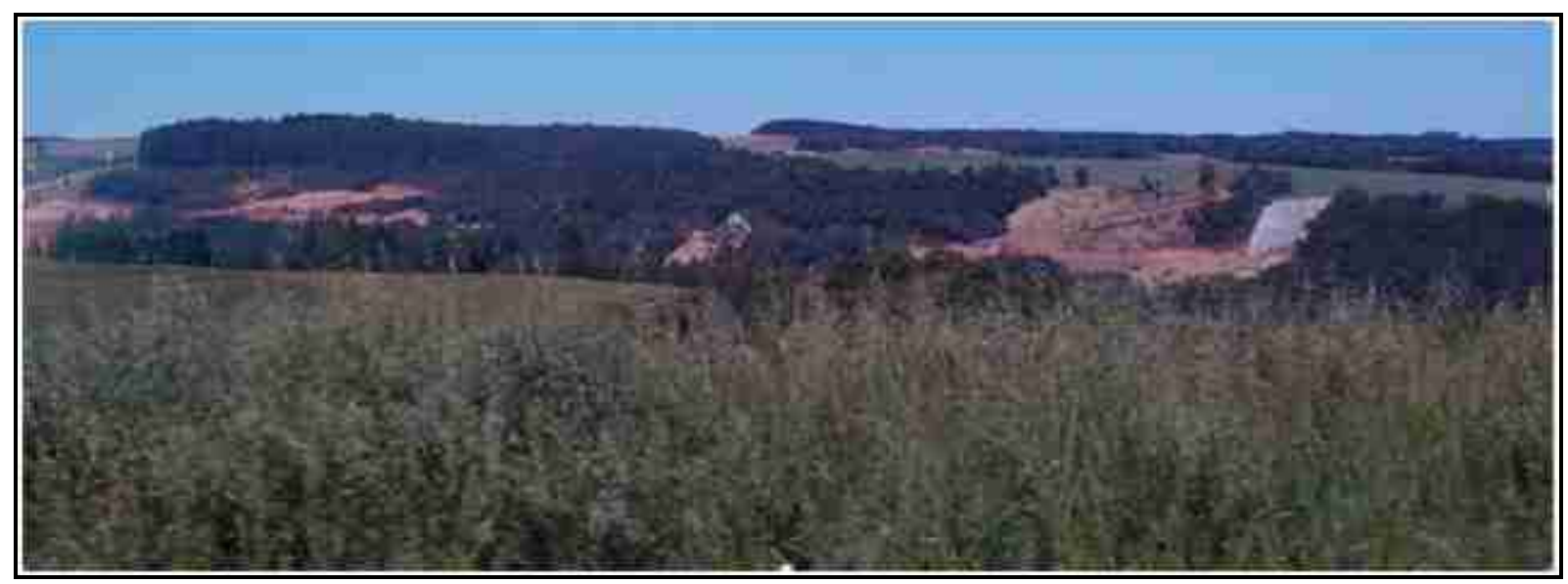

Fonte: Autores, 2018.

Ainda tem-se o impacto relacionado a desmobilização de mão de obra contratada ao final das obras, pois, muitos dos trabalhadores locais que participaram 
da construção da $\mathrm{PCH}$ são apenas temporariamente contratados, os quais dependeram de novas contratações futuras para a obtenção de renda. Sendo este impacto caracterizado como negativo pela flutuação que estes trabalhadores têm em sua renda mensal.

Como impactos ligeiramente negativos obteve-se aspectos relacionados com a qualidade da água, interferência no uso do solo, alojamentos e instalações durante as obras, resíduos sólidos, esgotamento sanitário, área de bota fora, proliferação de vetores, diminuição da pesca, interferência em terras vizinhas e no potencial turístico, perda de áreas de pastagem e risco de acidente de trabalho.

No que se refere a interferência no uso do solo, a construção alterou determinados uso do solo como é ocaso das vegetações suprimidas e de áreas agricultáveis atingidas. No entanto, como pode-se analisar pelos resultados dos mapeamentos expressos na Tabela 2 e representados pelas Figuras 16, 17 e 18, não houve significativos impactos. Pois, somando as áreas de agricultura, pastagem e solo exposto do ano de 2013, 2015 e 2017, obteve-se que, respectivamente, 72,9\%, 73,7\% e $68,8 \%$ que correspondem a área_antropizada. E 27,1\%,26,3\% e 31,2\% correspondem a área de mata.

Tabela 2 - Resultados referentes ao uso e ocupação do solo da bacia hidrográfica do Rio Covó.

\begin{tabular}{ccccc}
\hline CLASSES DE USO & \% da área - 2013 & \% da área - 2015 & \% da área - 2017 \\
\hline Água & 0,1 & 0,0 & 0,0 \\
Mata & 27,1 & 26,3 & 31,2 \\
Pastagem & 16,4 & 22,6 & 28,4 \\
Solo Exposto & 18,4 & 19,6 & 13,5 \\
Atividade Agrícola & 38,1 & 31,5 & 26,9 \\
\hline
\end{tabular}

Fonte: Autores, 2018.

Figura 16 - Uso e ocupação do solo da bacia hidrográfica do Rio Covó no ano de 2013. 
20| Avaliação dos impactos ambientais gerados na implantação das pequenas centrais hidrelétricas Canhadão e Tigre no Sudoeste do Paraná, pelo método RIAM

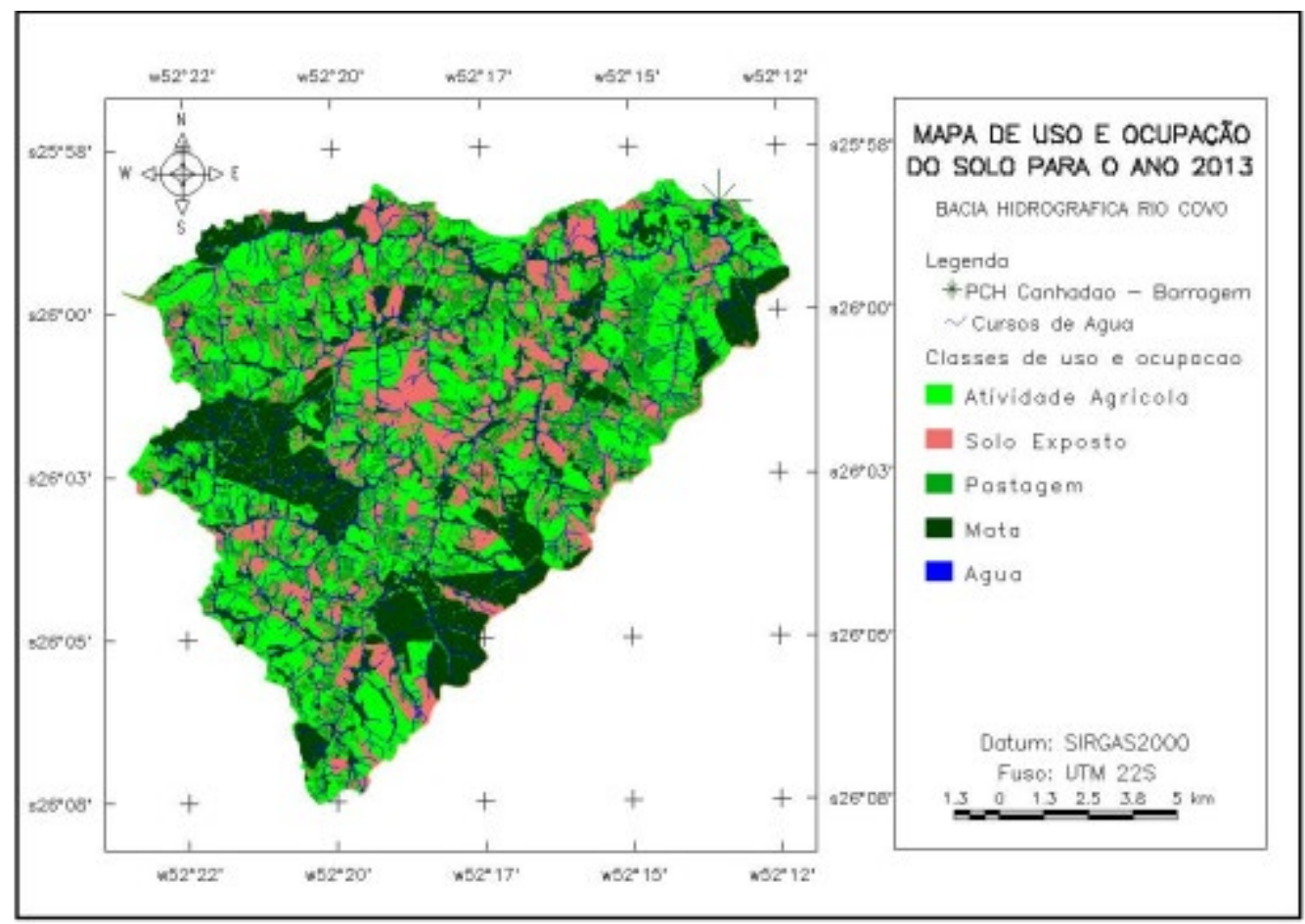

Fonte: Autores, 2018.

Figura 17 - Uso e ocupação do solo da bacia hidrográfica do Rio Covó no ano de 2015.

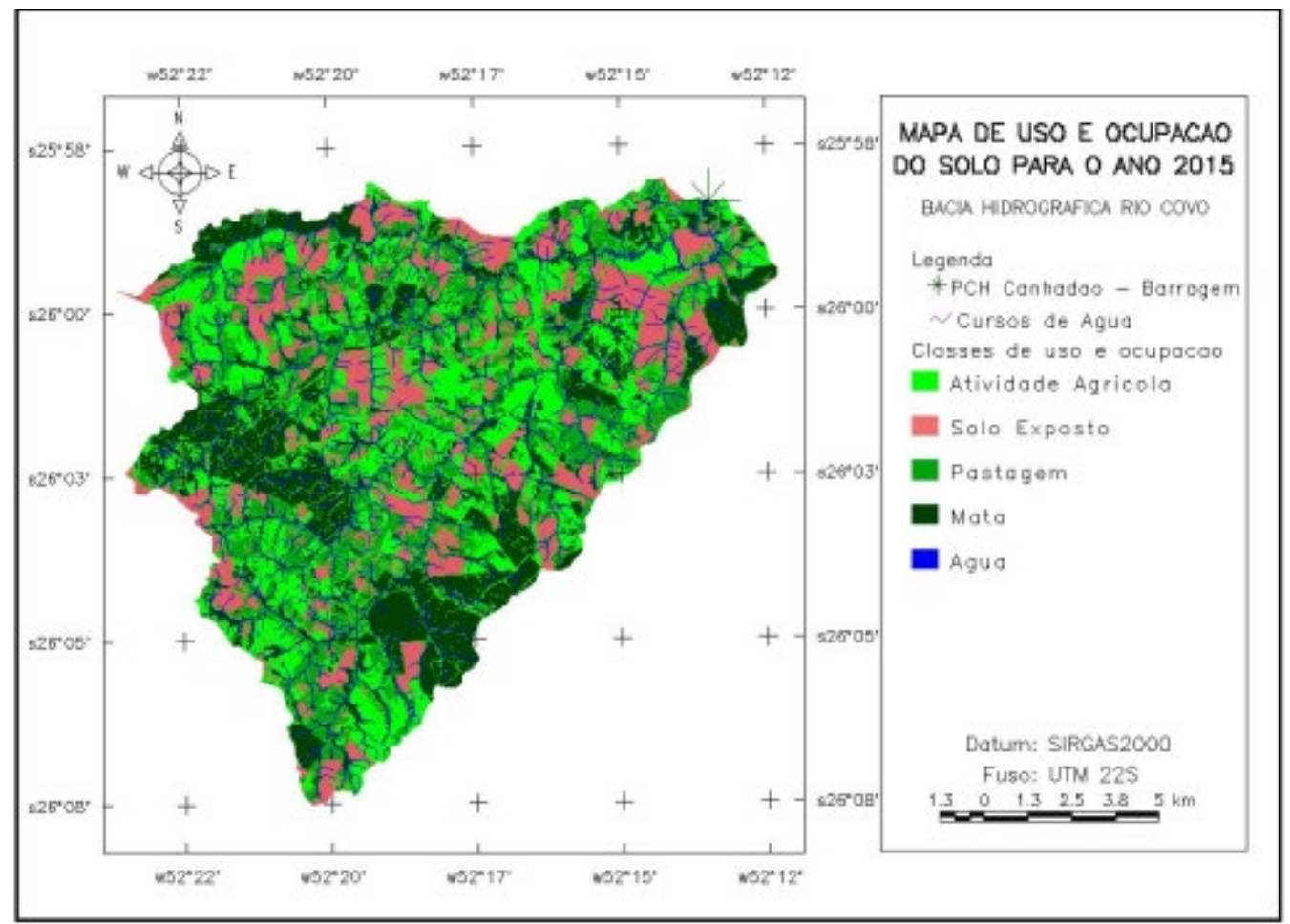

Fonte: Autores, 2018

Figura 18 - Uso e ocupação do solo da bacia hidrográfica do Rio Covó no ano de 2017. 


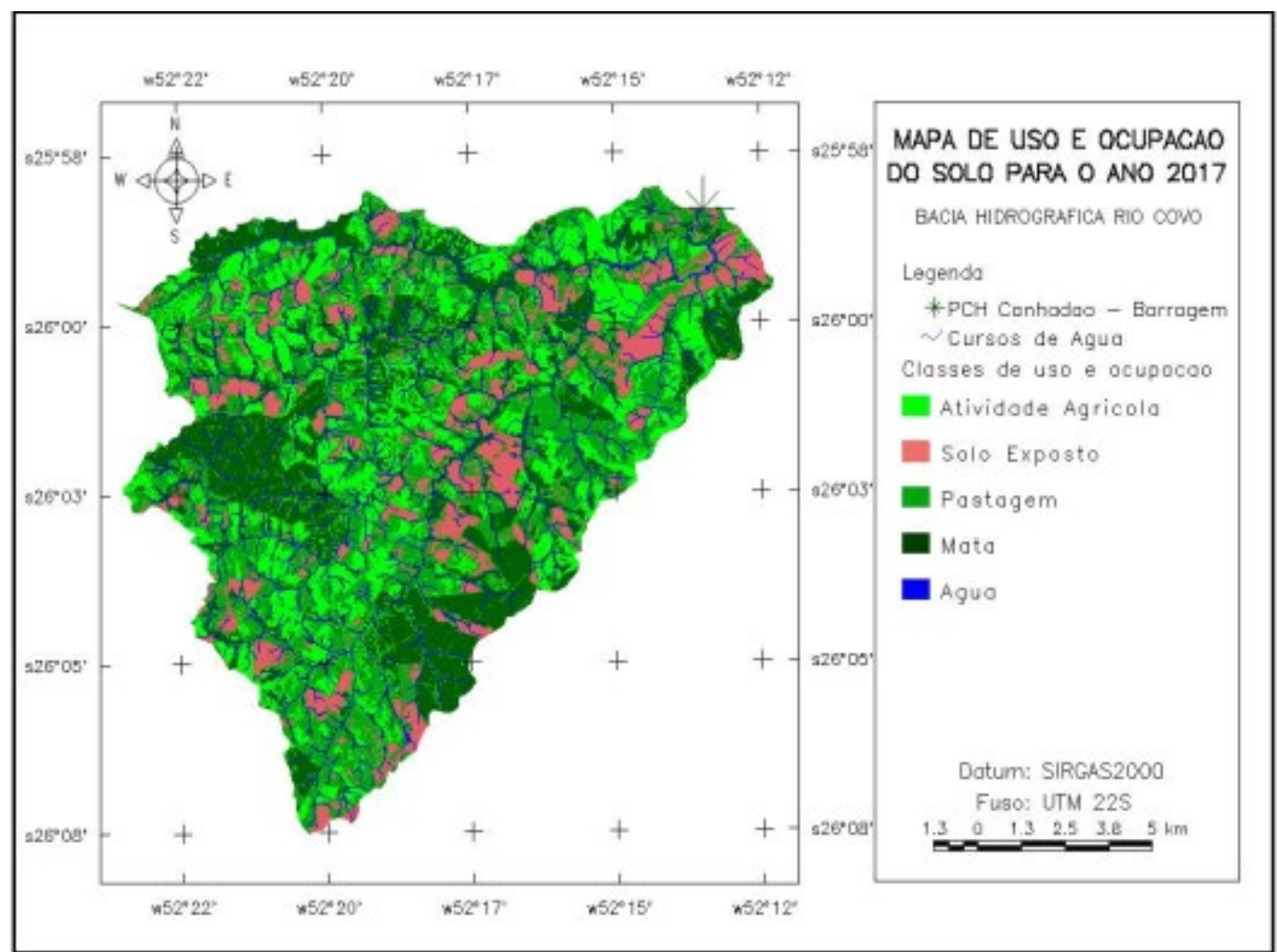

Fonte: Autores, 2018.

Sobre os alojamentos/instalações para a fase de implantação da $\mathrm{PCH}$, salientase que este impacto acarreta também a geração de resíduos sólidos, o esgotamento sanitário.

Como a PCH procurou utilizar-se dos próprios materiais que retirava dos locais deconstrução para realocar onde havia necessidade, então, quanto aos impactos referentes a área de bota fora não foram considerados significativos.

A proliferação de vetores é um impacto acarretado por alterações como a supressão de vegetação e o reservatório. Tal impacto não foi mensurado nesta pesquisa, mas considerado, pois, se não houverem medidas mitigadoras eficientes para todos os impactos, este será um fator negativo no futuro. Com a implantação da PCH e as alterações realizadas no corpo hídrico outra consequência que pode ser vir a aparecer é em relação a diminuição da pesca na localidade.Também tem-se o impacto referente a interferência em terras vizinhas e perda de áreas de pastagem, os quais percebeu-se que houve esta interferência masque a mesma não foi considerada como 
significativa. Quanto aos riscos de acidente de trabalho, os mesmos existem pela natureza das obras que são realizadas, mas verificou-se que medidas preventivas são aplicadas para evitar a ocorrência dos mesmos. Neste sentido, a empresa responsável pela obra, realiza dentre outros programas, os subprogramas de capacitação de mão de obra local e de saúde e segurança da mão de obra.

E por fim, o potencial turístico foi percebido como um impacto negativo, mas não foi considerado significativo pelo fato que a localidade de implantação da $\mathrm{PCH}$ não foi diagnosticada como um local de uso contínuo da população para fins de lazer. E neste sentido, caberia ainda futuros investimentos relacionados ao desenvolvimento do município, em relação a turismo, podendo, os sócios da PCH e o município, utilizar-se destes locais para tais finalidades. Para tanto, este impacto transita entre ser de caráter negativo e positivo.

Iniciando os impactos positivos, obteve-se como impacto significativamente positivo a rede viária e suas benfeitorias.

$\mathrm{Na}$ sequência como impactos moderadamente positivos obtiveram-se a oportunidade de emprego, novas oportunidades para a economia, o aumento de arrecadação tributária para o município e as indenizações e regularizações.

No que refere-se a oportunidade de emprego, considerado como um impacto positivo,de forma direta verificou-se que no mês de julho de 2016, fase de construção, haviam 65 trabalhadores envolvidos com a obra, sendo que $38 \%$ dos funcionários residiam em Mangueirinha, 15\% em Reserva do Iguaçu e $8 \%$ em Foz do Jordão, municípios vizinhos, ou seja, $61 \%$ dos trabalhadores residem na região (FORTE, 2016). Ademais, tem-se os trabalhadores envolvidos de forma indireta com o empreendimento, como por exemplo, os funcionários de empresas que fornecem serviços e máquinas para a construção da $\mathrm{PCH}$.

Relacionado a oportunidades de empregos, tem-se as novas oportunidades para a economia, pois para além da fase de construção, quando em funcionamento a 
PCH gera energia fomentando também o mercado de trabalho. Com a implantação do empreendimento, o município aumentará suas arrecadações tributárias.

Sobre as indenização e regularizações, pode-se verificar que dentre os lindeiros estes estão satisfeitos com a indenização recebida pela construção da $\mathrm{PCH}$ em suas terras.

E por fim, como ligeiramente positivo obteve-se a maior oferta de energia comconsequente contribuição para a redução de custos relacionados a outras fontes de energia, pois, com a geração de mais $10 \mathrm{MW}$ (potência da PCH Canhadão), terá mais oferta de energia, estando, de certa forma, contribuindo para que não ocorram as grandes faltas de energia e para a não necessidade de ativação de outras fontes consideradas mais caras ou não renováveis.

Para o caso da PCH Tigre realizou-se também uma RIAM, a qual está apresentada na Tabela 3.

Referente aos impactos significativamente negativos foram verificados a alteração da descarga a jusante em função do período de enchimento do reservatório e/ou de desvio permanente do rio, a inundação da vegetação com perda de patrimônio vegetal e o desmatamento dos locais das obras com prejuízo da produção florestal.

A alteração da descarga a jusante em função do período de enchimento do reservatório e/ou de desvio permanente do rio, é um impacto verificado principalmente entre o período de construção do barramento e do desvio e do enchimento do reservatório e do canal, mas é considerado um dos principais impactos negativos pela alteração que aquele ambiente sofre naquele momento. Período esse que a possibilidade do estresse causado, pelas alterações bruscas da descarga a jusante, na fauna aquática daquele local pode ser bastante prejudicada.

Tabela 3 - Matriz de avaliação de impacto rápido da PCH Tigre. 
24| Avaliação dos impactos ambientais gerados na implantação das pequenas centrais hidrelétricas Canhadão e Tigre no

Sudoeste do Paraná, pelo método RIAM

\begin{tabular}{|c|c|c|c|c|c|c|c|c|c|c|}
\hline & COMPONENTES & A1 & $\mathrm{A} 2$ & AT & $\mathrm{B} 1$ & B2 & B3 & BT & ES & $\mathrm{RB}$ \\
\hline PC1 & $\begin{array}{l}\text { Alteração da descarga a jusante pelo período } \\
\text { de enchimento e desvio do rio }\end{array}$ & 3 & -2 & -6 & 3 & 2 & 2 & 7 & - & $-D$ \\
\hline $\mathrm{PC2}$ & Assoreamento do reservatório & 2 & -2 & -4 & 2 & 2 & 3 & 7 & $\begin{array}{c}- \\
28\end{array}$ & $-C$ \\
\hline PC3 & Qualidade da água & 2 & -2 & -4 & 2 & 2 & 3 & 7 & $\begin{array}{c}- \\
28\end{array}$ & $-\mathrm{C}$ \\
\hline PC4 & Processos erosivos & 2 & -2 & -4 & 2 & 2 & 3 & 7 & $\overline{28}$ & $-C$ \\
\hline PC5 & $\begin{array}{l}\text { Degradação das áreas utilizadas pela } \\
\text { exploração de material de construção }\end{array}$ & 2 & -2 & -4 & 3 & 3 & 2 & 8 & $\begin{array}{c}- \\
32\end{array}$ & $-\mathrm{C}$ \\
\hline PC6 & Interferência no uso do solo & 1 & -1 & -1 & 3 & 3 & 2 & 8 & -8 & $-A$ \\
\hline PC7 & Alteração do ambiente de lótico para lêntico & 2 & -2 & -4 & 3 & 3 & 2 & 8 & 32 & $-\mathrm{C}$ \\
\hline PC8 & Alteração do habitat & 3 & -1 & -3 & 3 & 2 & 2 & 7 & $\overline{21}$ & $-C$ \\
\hline PC9 & Resíduos sólidos & 2 & -1 & -2 & 2 & 1 & 1 & 4 & -8 & $-A$ \\
\hline PC10 & Esgotamento sanitário & 2 & -1 & -2 & 2 & 1 & 1 & 4 & -8 & $-A$ \\
\hline PC11 & Área de bota-fora & 1 & -1 & -1 & 3 & 3 & 2 & 8 & -8 & $-A$ \\
\hline PC12 & Ruídos de explosões e máquinas + emissões & 2 & -2 & -4 & 2 & 2 & 3 & 7 & 28 & $-\mathrm{C}$ \\
\hline PC13 & Rede viária & 2 & 3 & 6 & 3 & 3 & 3 & 9 & 54 & $\mathrm{D}$ \\
\hline PC14 & Alojamentos/instalações durante as obras & 1 & -1 & -1 & 2 & 2 & 1 & 5 & -5 & $-A$ \\
\hline PC15 & Proliferação e vetores & 1 & -1 & -1 & 2 & 2 & 3 & 7 & -7 & $-A$ \\
\hline PC16 & Alteração na paisagem como um todo & 3 & -1 & -3 & 3 & 3 & 3 & 9 & 27 & $-\mathrm{C}$ \\
\hline BE1 & $\begin{array}{l}\text { Inundação da vegetação com perda de } \\
\text { patrimônio vegetal }\end{array}$ & 3 & -2 & -6 & 3 & 2 & 3 & 8 & - & $-D$ \\
\hline BE2 & $\begin{array}{c}\text { Perda de habitats naturais e da disponibilidade } \\
\text { alimentar para a fauna terrestre }\end{array}$ & 2 & -2 & -4 & 2 & 2 & 3 & 7 & - & $-C$ \\
\hline BE3 & Diminuição da pesca & 2 & -1 & -2 & 1 & 2 & 1 & 4 & -8 & $-A$ \\
\hline BE4 & $\begin{array}{l}\text { Desmatamento dos locais das obras com } \\
\text { prejuízo da produção florestal }\end{array}$ & 3 & -2 & -6 & 3 & 2 & 3 & 8 & - & $-D$ \\
\hline BE5 & $\begin{array}{c}\text { Ameaças de atropelamento de animais } \\
\text { silvestres }\end{array}$ & 3 & -1 & -3 & 3 & 2 & 3 & 8 & - & $-C$ \\
\hline SC1 & Interferência em terras vizinhas & 2 & -1 & -2 & 1 & 1 & 1 & 3 & -6 & $-A$ \\
\hline $\mathrm{SC2}$ & Interferência no potencial turístico & 3 & -1 & -3 & 1 & 1 & 1 & 3 & -9 & $-A$ \\
\hline EO1 & Oportunidade de emprego & 3 & 1 & 3 & 2 & 2 & 3 & 7 & 21 & C \\
\hline $\mathrm{EO} 2$ & Novas oportunidades para a economia & 3 & 1 & 3 & 3 & 2 & 3 & 8 & 24 & $\mathrm{C}$ \\
\hline $\mathrm{EO} 3$ & Maior oferta de energia & 3 & 1 & 3 & 1 & 1 & 1 & 3 & 9 & A \\
\hline EO4 & Perda de área de pastagem & 1 & -1 & -1 & 3 & 3 & 3 & 9 & -9 & $-A$ \\
\hline EO5 & Aumento de arrecadação tributária municipal & 2 & 2 & 4 & 3 & 2 & 3 & 8 & 32 & $\mathrm{C}$ \\
\hline EO6 & Riscos de acidentes de trabalho & 2 & -1 & -2 & 2 & 1 & 1 & 4 & -8 & $-A$ \\
\hline EO7 & $\begin{array}{c}\text { Indenização e regularizações para com os } \\
\text { lindeiros }\end{array}$ & 2 & 2 & 4 & 3 & 3 & 2 & 8 & 32 & C \\
\hline EO8 & $\begin{array}{l}\text { Desmobilização de mão de obra contratada ao } \\
\text { final das obras }\end{array}$ & 3 & -2 & -6 & 1 & 2 & 1 & 4 & - & $-\mathrm{C}$ \\
\hline
\end{tabular}

Fonte: Autores, 2018.

O canal, fica a meia encosta do rio, como pode-se verificar na Figura 19, seu comprimento é de 1.050 metros, sendo que sua forma é trapezoidal com base de 4,00 
metros e profundidade de aproximadamente 2,5 metros (RECITECH AMBIENTAL, 2016). Nos locais com solo exposto utilizou-se de revestimento de geomembrana de PEAD - Polietileno de alta densidade com o objetivo de impermeabilizá-lo.

Figura 19 - Localização esquemática da PCH.

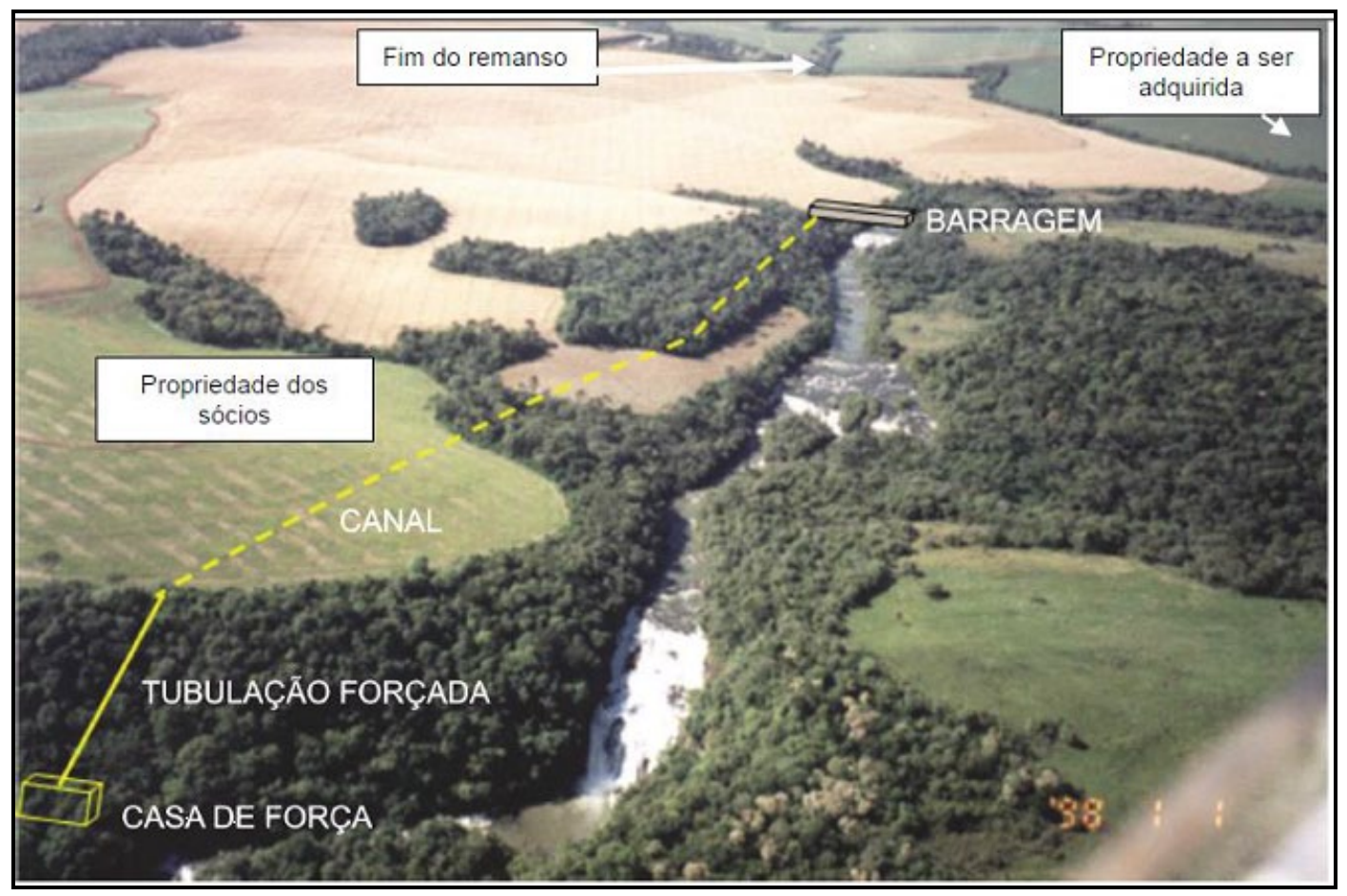

Fonte: Recitech ambiental.

Segundo o RAS realizado para a $\mathrm{PCH}$, para o enchimento do reservatório levaram-se dois dias e manteve-se uma vazão afluente próxima à vazão com $50 \%$ de permanência (RECITECH AMBIENTAL. 2016). No entanto, para aquele meio houve alteração e esta foi significativa, gerando estresse para os indivíduos ali presentes, pois são dois dias de que a vazão do rio diminuiu consideravelmente.

A área alagada total foi de 65 ha, dos quais 8,32 ha referem-se a calha natural do rio, ou seja, a área efetivamente alagada é de 56,7 ha. E a área alagada para o reservatório da $\mathrm{PCH}$ foi de 41,66 ha. De acordo com o Art. $2^{\circ}$ da Resolução normativa $\mathrm{n}^{\circ} 673$ (BRASIL, 2015), são empreendimentos considerados PCHs aqueles com área do reservatório que não passam de $13 \mathrm{~km}^{2}$, excluindo a calha do leito regular do rio. Portanto, a área inundada é consideravelmente baixa, apesar 
de a $\mathrm{PCH}$ ter potência para gerar $9 \mathrm{MW}$ e não $30 \mathrm{MW}$ que poderia ser considerado para o caso de reservatórios maiores. Mas essa área ser considerada baixa não significa que não acarretou impactos significativos, pois, como já mencionado nesta pesquisa deve-se considerar o todo envolvido.

Com a implantação da PCH a inundação da vegetação com perda de patrimônio vegetal trouxe o "alagamento de 33,34 ha de floresta secundária em estágio inicial/médio de regeneração" (RECITECH AMBIENTAL, 2016).

O desmatamento dos locais das obras e consequente prejuízo da produção florestal, ao qual, somando áreas de obras e aberturas de estradas o desmatamento foi de 25,4 ha (RECITECH AMBIENTAL, 2016). Destaca-se a significância deste impacto, pelo fato de serem suprimidas áreas de vegetação nativa, habitat de fauna terrestre e alada.

Referente às áreas de supressão vegetal e alagamento "o lago terminará aproximadamente a 2,50 km da barragem, ocupando áreas de pastos e lavouras temporárias de APP's em uma faixa de 3,50 km seguindo a calha do rio", além disto, "ocorrerá à elevação do nível da água formando um lago que irá ocupar cerca de 30 ha das três propriedades envolvidas, somando a APP e canteiro de obras, teremos uma área de impacto as propriedades de 101,55 ha" (RECITECH AMBIENTAL).

Com tais impactos, destaca-se a importância das medidas mitigadoras, neste sentido, segundo o que está proposto no RAS da $\mathrm{PCH}$ é que a APP a ser recuperada na margem no lago terá 50 m - Figura 20, enquadrando-se no que é exigido pela Lei $n^{\circ}$ 12.727._No caso da construção da casa e força e demais partes da $\mathrm{PCH}$, e abertura de estradas, terá a supressão da vegetação "dever-se-á apresentar medidas compensatórias, podendo ser a incorporação proporcional, destas áreas, na APP que será recuperada" (RECITECH AMBIENTAL, 2016).

Figura 20 - Limites da área de alagamento e recomposição da mata ciliar. 


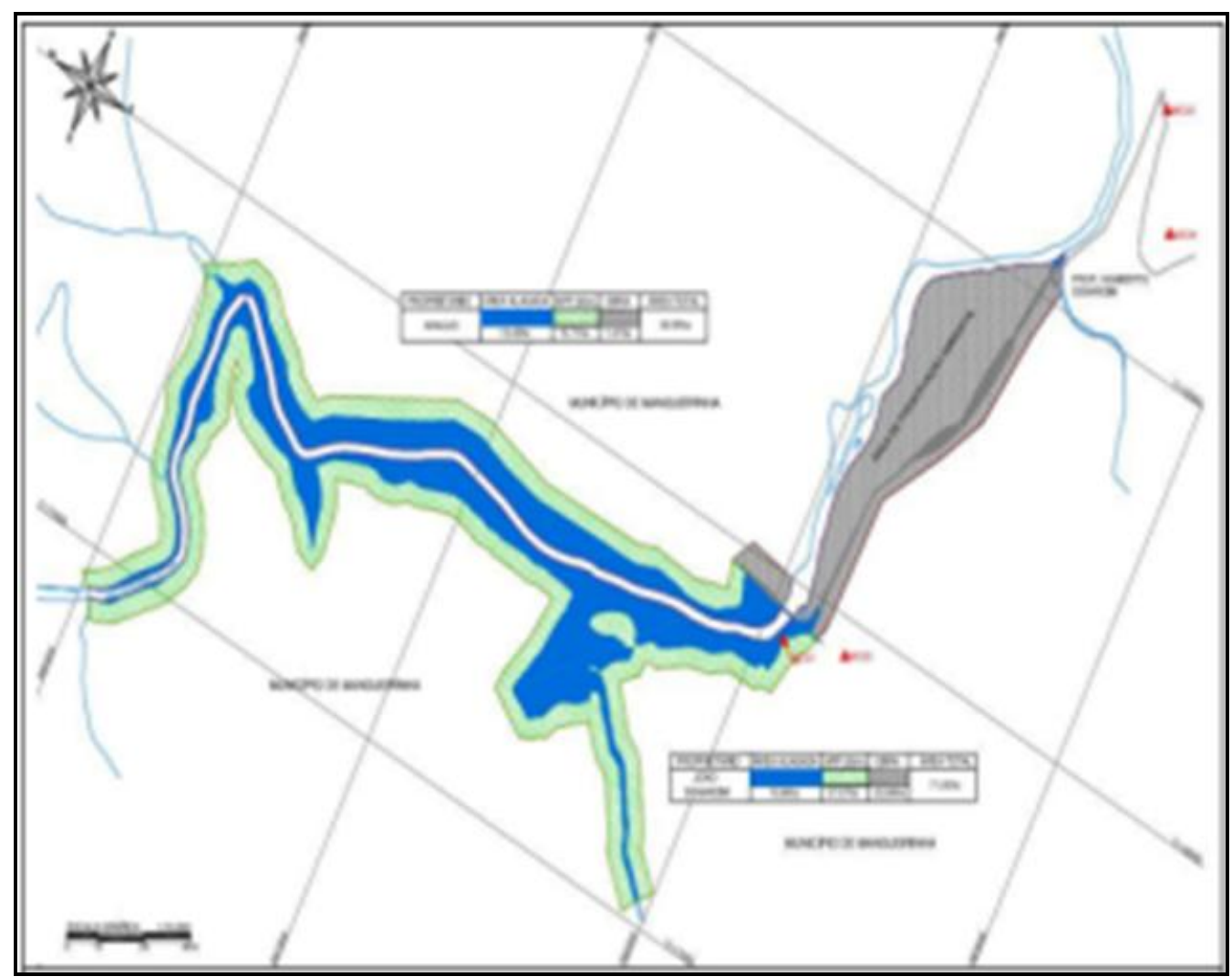

Fonte: Projeto Básico da PCH apud_Recitech ambiental, 2016.

Sobre o componente desmatamento dos locais das obras, segundo a Lei $\mathrm{n}^{\circ}$ 12.727, de 17 de outubro de 2012 que dispõe sobre a proteção da vegetação nativa, em seu Art $5^{\circ}$ deixa claro que

"Na implantação de reservatório d'água artificial destinado a geração de energia ou abastecimento público, é obrigatória a aquisição, desapropriação ou instituição de servidão administrativa pelo empreendedor das Áreas de Preservação Permanente criadas em seu entorno, conforme estabelecido no licenciamento ambiental, observando-se a faixa mínima de 30 (trinta) metros e máxima de 100 (cem) metros em área rural, e a faixa mínima de 15 (quinze) metros e máxima de 30 (trinta) metros em área urbana" (BRASIL,2012,grifo da autora).

$\mathrm{Na}$ sequência obteve-se os impactos moderadamente negativos como o assoreamento do reservatório, os processos erosivos, a degradação das áreas utilizadas pela exploração de material de construção e pelas obras temporárias de construção civil (corte e movimentação de solo e rocha), a alteração do ambiente de lótico para lêntico, a qualidade da água, a alteração do habitat, a perda de habitats naturais e da disponibilidade alimentar para a fauna terrestre, as ameaças de atropelamento de animais silvestres, os ruídos de explosões e máquinas e as emissões 
geradas, a desmobilização de mão de obra contratada ao final das obras e a alteração na paisagem como um todo.

O assoreamento do reservatório, como todos os impactos dependeram das ações de mitigação. Ações estas de suma importância tanto para o meio quanto na manutenção e operação da PCH. A ocorrência deste impacto tem sua maior significância na fase de implantação, pela movimentação de solo, sendo de difícil quantificação e temporário (RECITECH AMBIENTAL), mas também ocorre na fase de operação, pois com o tempo e o revolvimento de solo a montante do barramento pode causar assoreamento, sendo um fator a ser considerado na manutenção da $\mathrm{PCH}$.

Os processos erosivos também dependem, tanto na fase de implantação quanto de operação, das medidas mitigadoras, pois são processos que intensificam sua significância e magnitude com o tempo caso não forem tomados os devidos cuidados. São vários os fatores que acarretam os processos erosivos, e também que são intensificados por tais processos, "o clima, a topografia, os materiais de origem, a biota e o tempo são os fatores que determinam as características dos solos e das quais depende o seu equilíbrio dinâmico. Qualquer mudança em uma dessas variáveis certamente irá afetar o solo" (BASTOS e FREITAS, 2010, p. 31).

No que refere-se a degradação das áreas utilizadas pela exploração de material de construção e pelas obras de construção civil tem-se que foram removidos materiais para a construção da $\mathrm{PCH}$ e também para a abertura de estradas de acesso aos locais de construção, além disto, utilizou-se de materiais retirados de jazidas próximas a construção (RECITECH AMBIENTAL). Com a construção das obras pode-se perceber impactos como, por exemplo, os cortes realizados tanto no solo quanto na rocha, que são vistos na construção de partes da $\mathrm{PCH}$, como demonstrados nas Figuras 21, 22 e 23.

Figura 21 - Barramento e desvio construídos, com plantações a sua margem esquerda e queda d'água natural a jusante. 


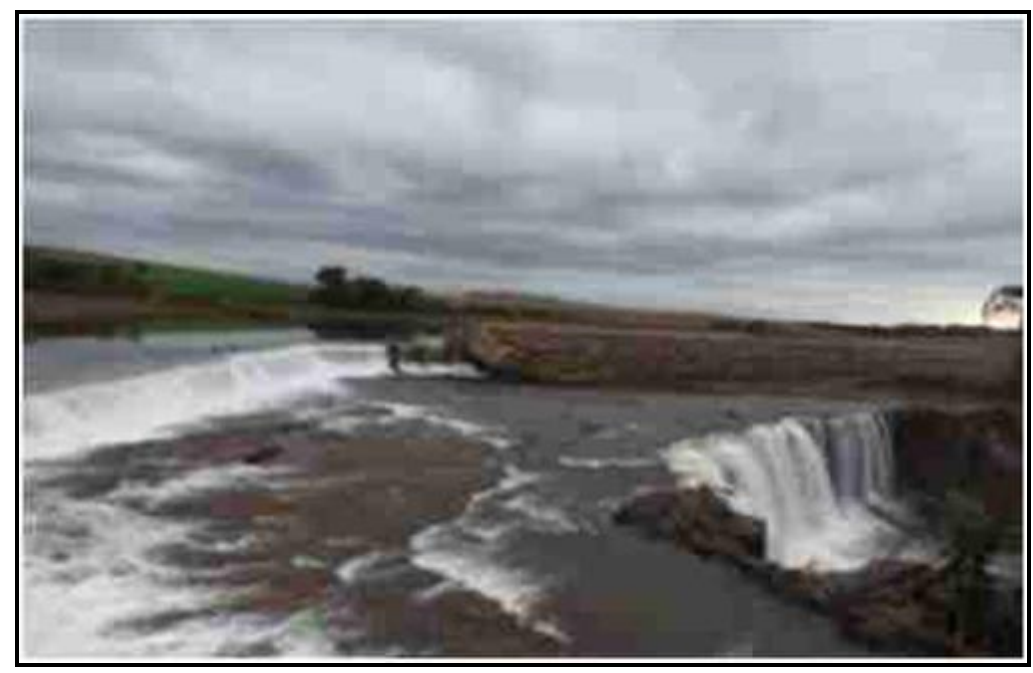

Fonte: Autores, 2018.

Figura 22 - Vista do canal impermeabilizado e preenchido, a direita do leito natural do rio.

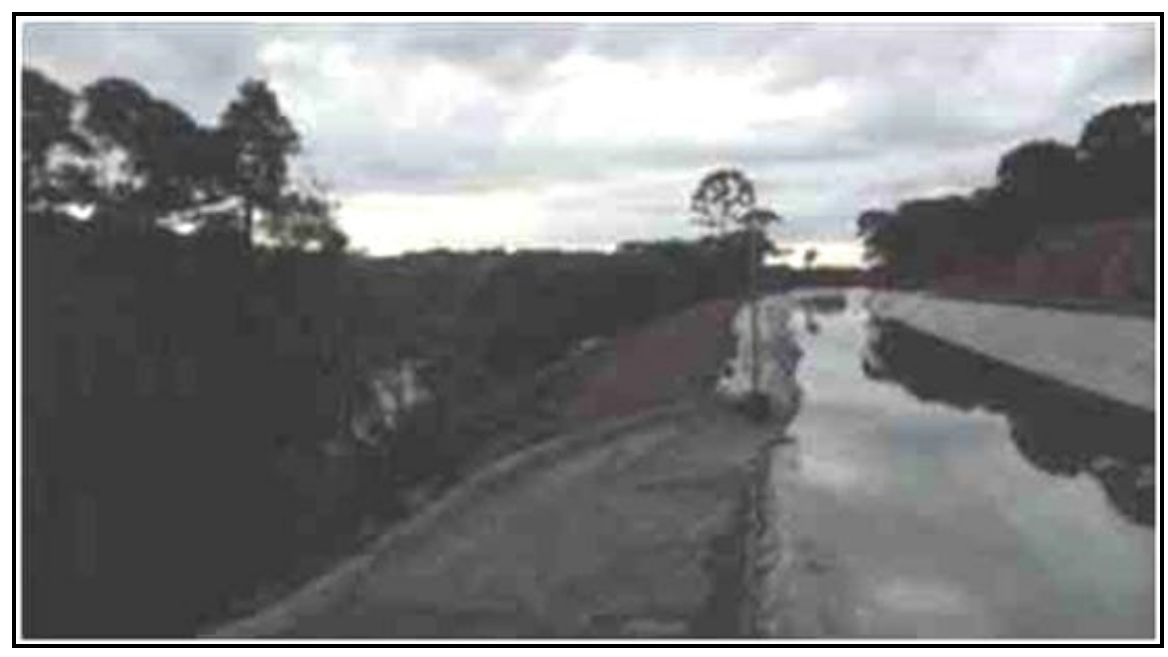

Fonte: Autores, 2018.

Com a Figura 23 pode-se ter uma vista do conduto forçado e da casa de força, nota-se o corte em solo e rocha realizado para a instalação deste conduto, sendo que o mesmo foi "ancorado em blocos de concreto engastados em rocha de boa qualidade" (RECITECH AMBIENTAL). Além disto, diagnosticou-se o desmatamento no local para tais construções.

Figura 23 - Vista do conduto forçado, destaque para o corte em solo e rocha realizado. 


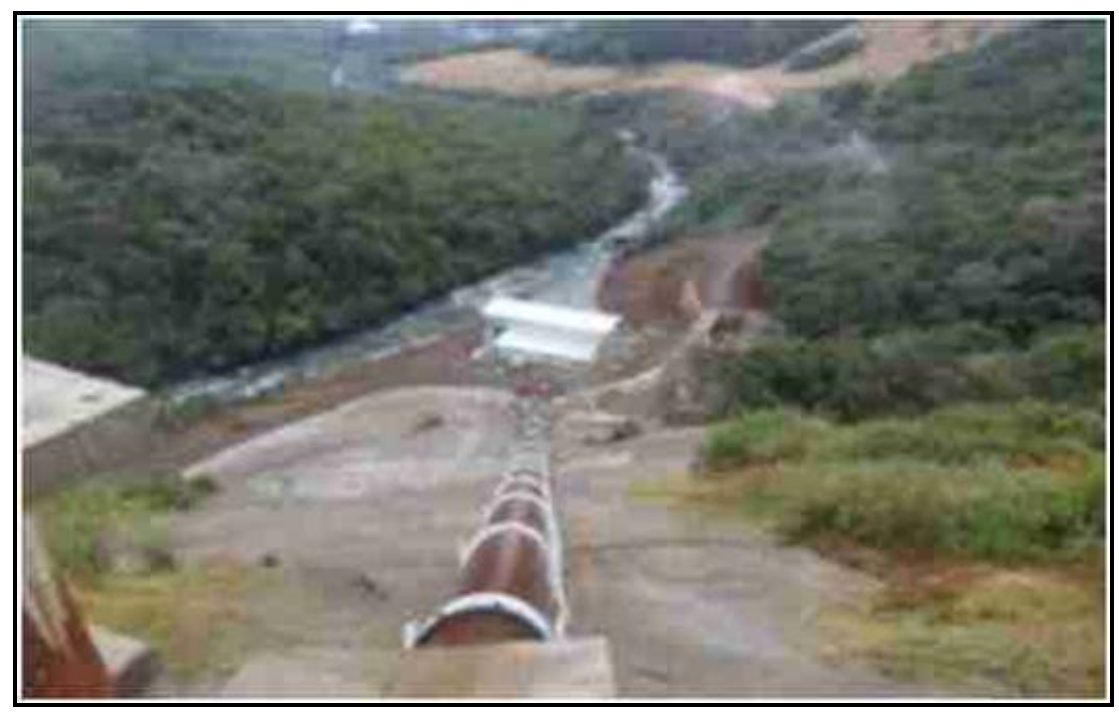

Fonte: Autores, 2018.

Além dos impactos identificados individualmente, tem-se que os mesmos são, na maioria dos casos, dependentes um do outro, ou seja, quanto maior o processo erosivo, mais assoreamento terá e a degradação das áreas utilizadas pela exploração de material de construção e pelas obras de construção civil está diretamente ligadas a estes dois impactos, pois auxilia na intensificação dos mesmos. Tais processos são explicados por alguns autores como:

"As encostas sofrem com a exploração de recursos naturais e com várias formas de
uso que os seres humanos têm dado a elas. Os solos, que são a parte mais externa
do relevo, acumulam toda a sorte de danos, em função de não se levar em conta,
na maioria das vezes, os riscos associados à sua utilização, o que se torna crítico,
por exemplo, nas relações entre encostas e as calhas fluviais. O que acontece numa
encosta acaba se refletindo sobre as calhas fluviais, podendo causar, por exemplo,
o assoreamento desses corpos líquidos, diminuindo a qualidade e a quantidade de
água. Assim, um corte de encosta para a construção de uma estrada, por exemplo,
precisa levar em conta esses fatores, porque do contrário incorrerá em custos de
manutenção ou recuperação altíssimos" (LIMA-E-SILVA, GUERRA, DUTRA, 2010,
p.227).

Naturalmente na localidade onde foi implantada a $\mathrm{PCH}$, existem quedas d'água naturais como pode-se verificar na Figura 19, o que propicia um ambiente lótico. No entanto, durante a construção e enchimento do reservatório e do canal, aquela localidade, naquele momento, sofreu alteração, pois o que antes era um ambiente considerado lótico transformou-se em um ambiente lêntico. De acordo com (RECITECH AMBIENTAL, 2016) na área de fim do remanso já era considerado um 
ambiente lêntico, e nesta área não haverá mudanças significativas, mas o diagnóstico desta pesquisa levou em consideração o local como um todo.

O monitoramento da qualidade da água para esta pesquisa não foi realizado, mas pela importância menciona-se que é na fase de implantação da PCH que se verifica a alteração maior na qualidade da água, pois ocorrem várias modificações no solo e ao redor do corpo hídrico, ocasionando alterações em alguns parâmetros. No entanto, devem-se ter cuidados também na fase de operação, por isso, segundo o RAS, a necessidade de limpeza do reservatório antes de seu enchimento, uma vez que se não houver a remoção da biomassa ali existente, com o tempo essa irá se degradar gerando alterações na qualidade da água.

No que refere-se a alteração do habitat, tem-se que houve alteração de um ambiente lótico para lêntico como descrito anteriormente, o que, por consequência, afeta a fauna aquática, porém considerou-se que a $\mathrm{PCH}$ opera a fio d'água e está devidamente estruturada como, por exemplo, com escadas que auxiliam no deslocamento destes. Quanto a fauna terrestre que também sofre com as altercações em seu habitat, e

\footnotetext{
"Dependendo da escala das alterações ou de quem é afetado na comunidade faunística, ocorrerão mudanças na composição ou nas populações[...] O normal tem sido a presença simultânea de alguns ou de todos eles (fatores que podem contribuir na sensibilidade de espécies), numa entropia desastrosa para a fauna aquática nacional" (ALMEIDA e TERTULIANO, 2010, p.159-160).
}

Tal impacto entrelaça-se com o impacto causado através da perda de habitats naturais e da disponibilidade alimentar para a fauna terrestre, pois pela supressão de vegetação, além da alteração e perda do habitat natural, consequentemente irá ser afetada a disponibilidade de alimento para a fauna ali existente. Ainda tem-se as ameaças de atropelamento de animais silvestres, que são acrescidas, já que estes sentem a necessidade de fugir em busca de um novo habitat e de alimento, fatores essenciais para a sobrevivência, e é nesta fuga que geralmente ocorrem os atropelamentos. 
Neste sentido, o que existe como proposta para mitigar os impactos é uma proposta de corredor entre um fragmento de vegetação e a mata ciliar, como verificado na Figura 24 (RECITECH AMBIENTAL).

Figura 24 - Fragmentos identificados e, possíveis locais para implantação de corredores ecológicos.

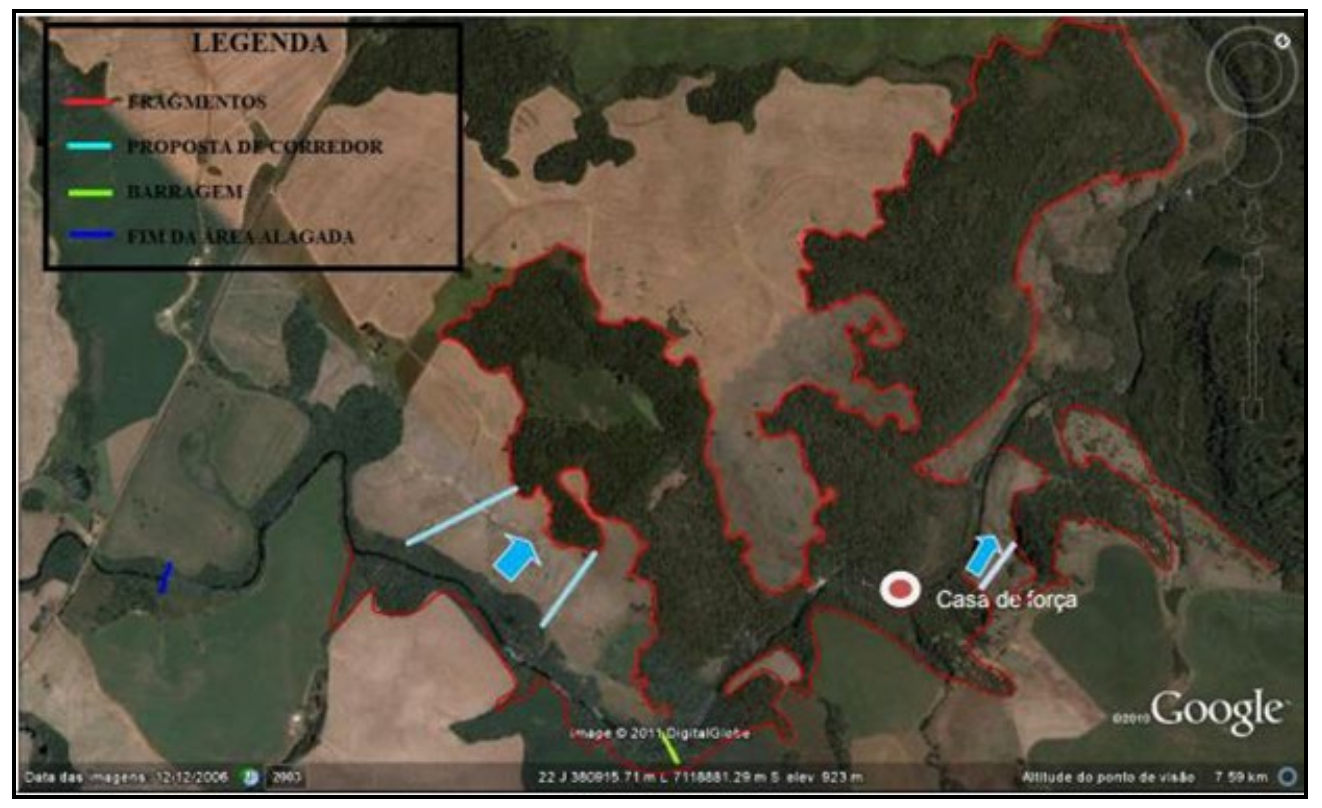

Fonte: Google Earth (2011), adaptado por Luiz Gustavo E. Vale apud Recitech ambiental, 2016.

Na fase de implantação há um acréscimo considerável de ruídos de explosões e de máquinas além disto, tem-se as emissões geradas neste processo. Tal poluição ocorre principalmente na exploração de materiais, na carga e descarga de matérias prima como solo e rochas, gerando poeira e através do trãnsito de veículos com a queima de combustível veicular. Tais poluentes são de difícil monitoramento e quando lançados se espalham na atmosfera, sendo assim de forma cumulativa com outros já existentes e que são gerados e lançados diariamente pela ação humana.

Ao final das obras, tem-se a desmobilização da mão de obra contratada, impacto considerado como sendo de importância regional e nacional, pois há vários profissionais envolvidos na implantação da $\mathrm{PCH}$. No caso de empresas e profissionais ligados a este tipo de trabalho, apesar de cada contratação ser temporária, sempre 
tem-se a necessidade de manutenção e a possibilidade de novos contratos de trabalhos. Mas, para os postos de trabalho gerados temporariamente na localidade da instalação, há uma alternância maior.

Ao final da fase de implantação pode-se ter uma visão geral da alteração na paisagem como um todo, sendo visualmente sentido impactos referentes a supressão de vegetação, e suas consequências na fauna e solo.

Sobre os impactos negativos, por fim, obteve-se os considerados como impactos ligeiramente negativos, ou seja, impactos negativos de menor significância para o meio quando comparados aos demais impactos, como a interferência no uso do solo, a perda de área de pastagem, a interferência em terras vizinhas, resíduos sólidos, esgotamento sanitário, área de bota-fora, as instalações e alojamentos durante as obras, a proliferação e vetores, a diminuição da pesca, a interferência no potencial turístico e os riscos de acidentes de trabalho.

A interferência no uso do solo pode ser resumida na supressão de vegetação, em parte nativa e na utilização de locais antes utilizados para agricultura, além disto, tem-se como interferência quando trata-se de acrescentar um empreendimento que antes não existia.No entanto, através dos resultados e mapeamentos demonstrados na Tabela 4 e Figuras 25, 26 e 27, aferiu-se que a localidade em questão tem suporte para empreendimentos deste porte e que não houve impactos significativos nos usos do solo.

Especificamente sobre a perda de área de pastagem, pela Tabela 4 verificase que houve aumento desta área. Sobre a interferência em terras vizinhas, segundo relatos de moradores lindeiros, os mesmos, ou não utilizavam diretamente as terras utilizadas para a implantação da $\mathrm{PCH}$, ou utilizavam pouco, o que com as negociações, concluíram que este quesito, não foi um impacto considerados como significativo. Mas para esta pesquisa, enquadrou-se ainda como negativo pois entende-se que teve esta interferência e alteração no meio. 
34| Avaliação dos impactos ambientais gerados na implantação das pequenas centrais hidrelétricas Canhadão e Tigre no Sudoeste do Paraná, pelo método RIAM

Tabela 4 - Resultados referentes ao uso e ocupação do solo da bacia hidrográfica do Rio Marrecas.

\begin{tabular}{c|c|c|c}
\hline CLASSES DE USO & $\begin{array}{c}\text { \% da área - } \\
\text { 2013 }\end{array}$ & \% da área - 2015 & \% da área - 2017 \\
\hline Água & 0,2 & 0,1 & 0,2 \\
Mata & 30,4 & 30,1 & 32,5 \\
Pastagem & 17,6 & 23,6 & 27,0 \\
Solo Exposto & 24,6 & 18,7 & 17,0 \\
Atividade Agrícola & 27,2 & 27,5 & 23,3 \\
\hline
\end{tabular}

Fonte: Autores, 2018.

Figura 25 - Uso e ocupação do solo da bacia hidrográfica do Rio Marrecas no ano de 2013.

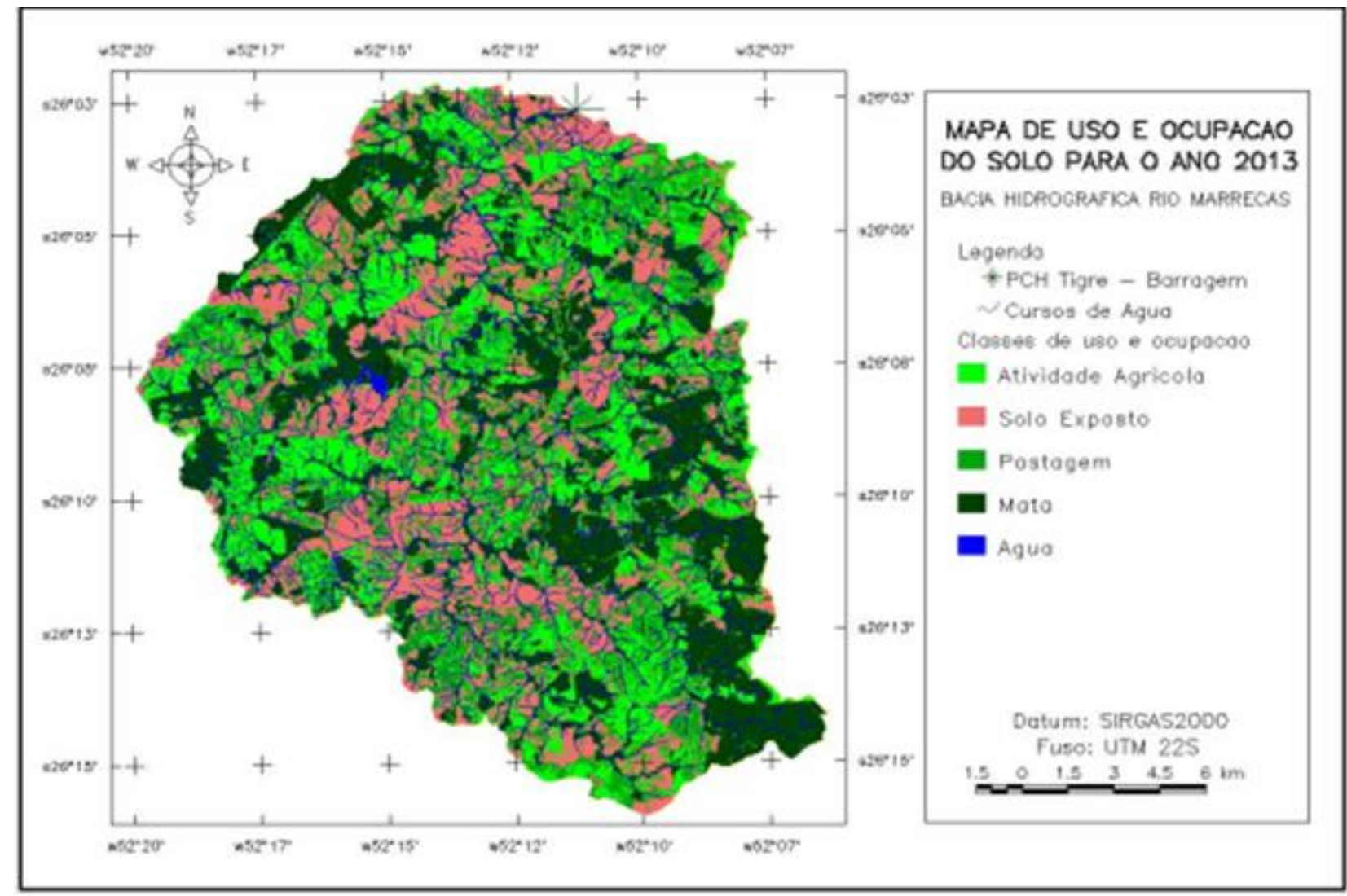

Fonte: Autores, 2018.

Figura 26 - Uso e ocupação do solo da bacia hidrográfica do Rio Marrecas no ano de 2015 


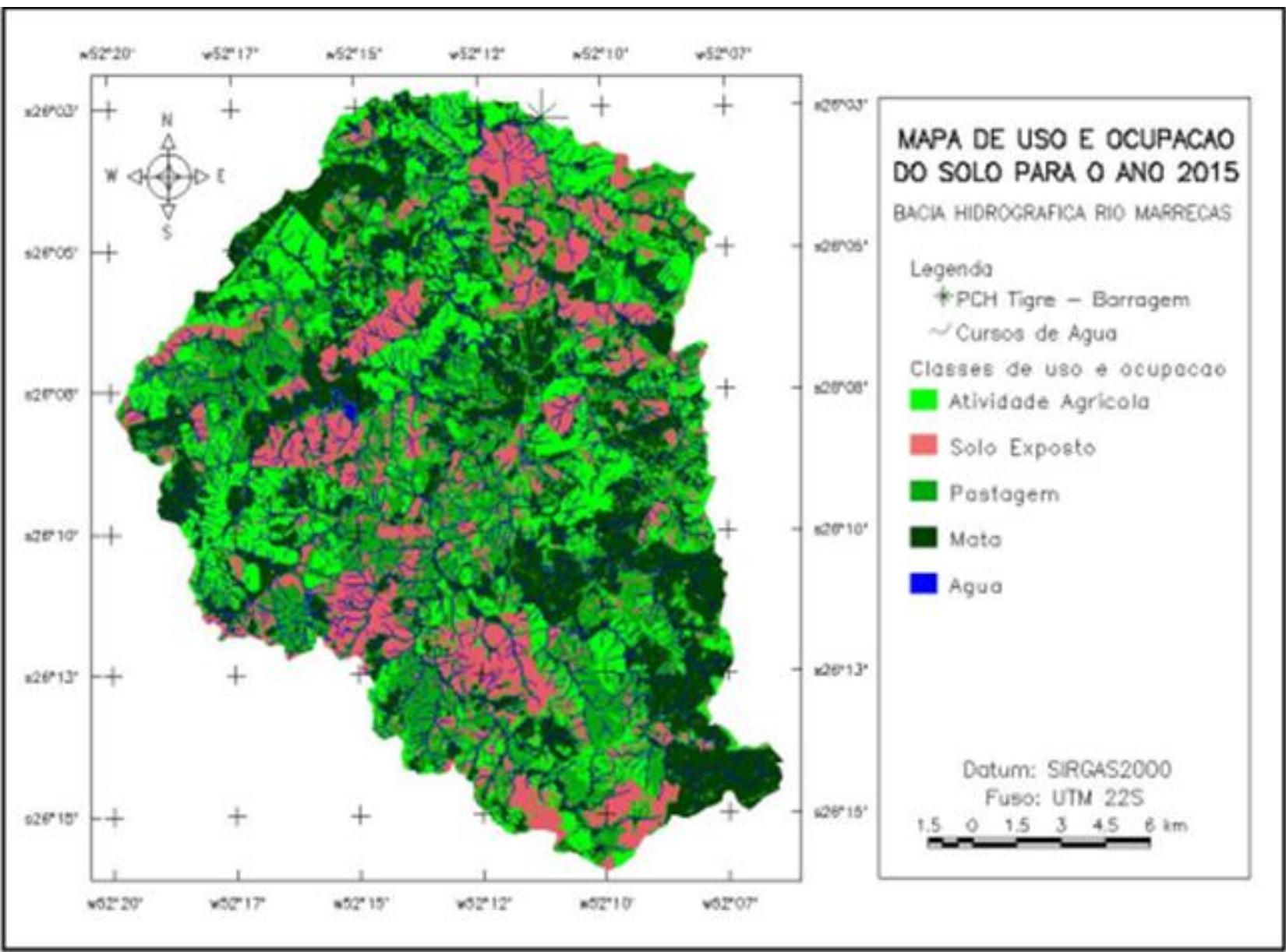

Fonte: Autores, 2018.

A área de bota-fora aparece como um impacto negativo, embora grande parte do que foi retirado para as obras reutilizou-se para aterramento, ainda teve materiais que precisaram ser realocados. Como no caso do corte das árvores que em parte foram depositadas fora da área destinada à preservação, posicionadas em partes da poligonal que contorna a APP do reservatório, servindo de abrigo e deslocamento para a fauna, e outra parte se encontra em processo de remoção para uso nas propriedades (A. MÜLLER, 2015).

Sobre os alojamentos/instalações durante as obras, houve a locação de uma residência no Distrito de Covó não tendo a necessidade de dormitórios no local da obra. Mas, foram necessárias outras construções, para o melhor andamento das obras, como o refeitório, uma pequena oficina, escritório e almoxarifado (A. MÜLLER, 2015), sendo que todas as instalações foram retiradas ao final da obra. 
Figura 27 - Uso e ocupação do solo da bacia hidrográfica do Rio Marrecas no ano de 2017.

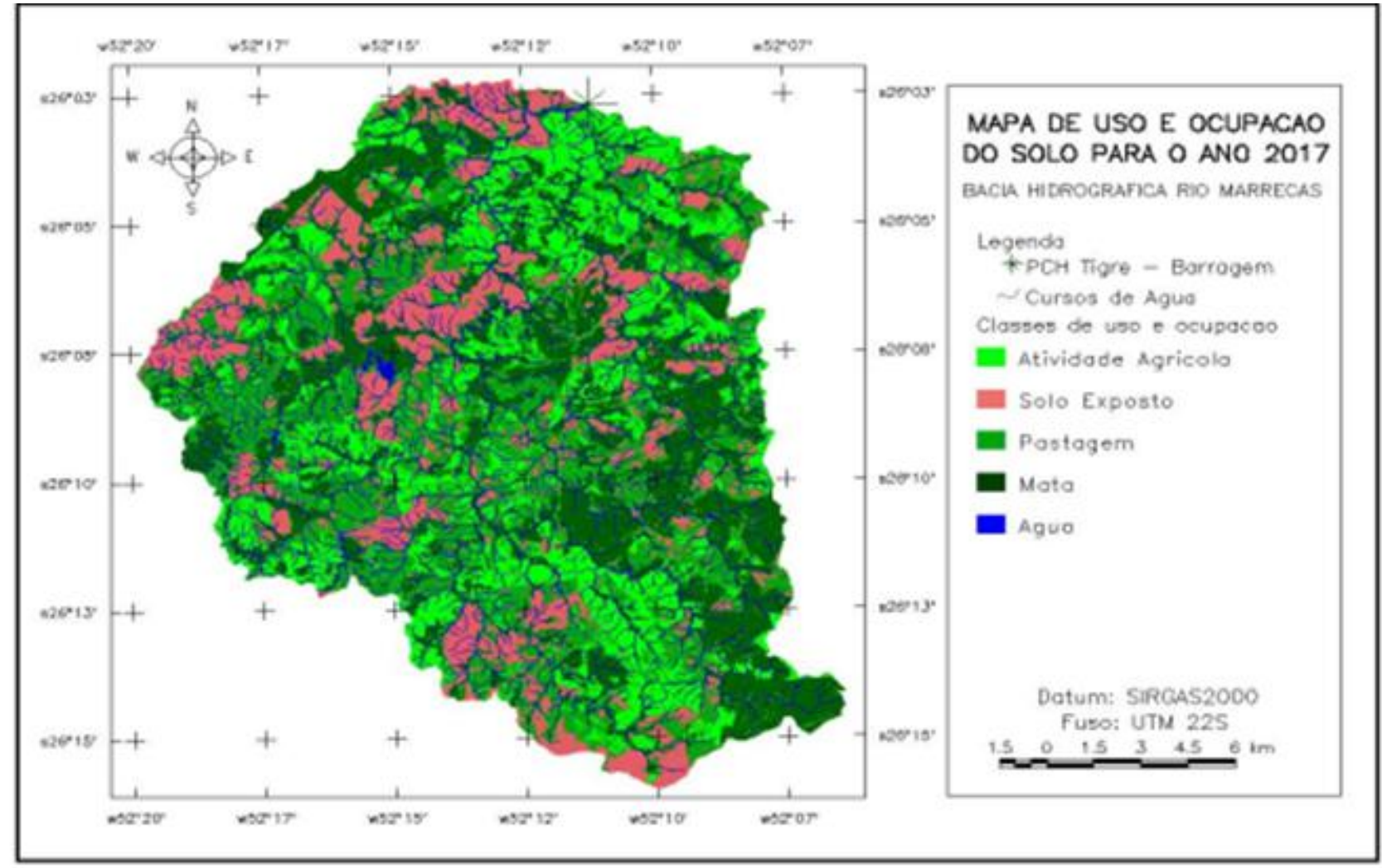

Fonte: Autores, 2018.

A proliferação de vetores onde há a supressão da vegetação e há disposição de resíduos e geração de efluentes é facilmente desenvolvida. Tal impacto foi considerado de permanência temporária por ocorrer em maior escala na fase de instalação, no entanto caso não haja manutenção adequada principalmente do canal e reservatório poderá se tornar permanente e cumulativo. Quanto aos riscos de acidente de trabalho, é um impacto de caráter negativo, mas existem prevenções para que nada ocorra.

Referente a interferência no potencial turístico, tem-se que no local da implantação da PCH há duas cachoeiras, anteriormente exploradas por moradores da região, apesar de, como destacado no RAS, não ter acesso ao local. A alteração neste ambiente ocorreu e destaca-se principalmente a vazão de água, modificada pelo barramento. Mas este impacto a princípio de caráter negativo, pode tornar-se, um impacto de caráter positivo, caso sejam viabilizadas, a caminho e no local da PCH, um 
itinerário para a população e visitantes conhecerem a $\mathrm{PCH}$ e as belas vistas naturais da localidade.

Como impacto significativamente positivo obteve-se a rede viária, impacto este verificado pela sua ampliação e melhoria que ficou evidente através das visitas in loco.

$\mathrm{Na}$ sequência, como impactos moderadamente positivos obteve-se a oportunidade de emprego, as novas oportunidades para a economia, o aumento de arrecadação tributária municipal e a indenização e regularizações para com os lindeiros.

Sobre a oportunidade de emprego tem-se que apesar de a grande gama de trabalhadores envolvidos no empreendimento serem temporários, gerasse empregos. A maioria, pois na fase de operação é necessária ao menos uma pessoa para monitoramento e também se considerou o pessoal para a manutenção da $\mathrm{PCH}$.

Como as novas oportunidades para a economia considerou-se tanto o durante a implantação da $\mathrm{PCH}$ que é necessário todo um leque de profissionais e empresas envolvidas, quanto o depois da construção, na fase de operação e, portanto, geração de energia, pois essa energia é gerada com um intuito o qual irá auxiliar na economia regional/nacional, seja para o funcionamento de mais postos de trabalho, e até para o caso da venda de energia para a concessionária responsável.

O município de Mangueirinha a médio e longo prazo terá aumento da arrecadação tributária municipal, principalmente com imposto sobre a circulação de mercadorias e serviços (RECITECH AMBIENTAL, 2016).

No caso dos lindeiros, houve indenização e regularizações pela utilização de parte das propriedades, e, não houve a necessidade de realocação destas famílias.

Por fim, entre os impactos ligeiramente positivos obteve-se a maior oferta de energia consequentemente contribuição para a redução de custos relacionados a outras fontes de energia, já que as PCHs no Brasil vem aumentando sua abrangência seja para diminuir tais custos vindos de energia geradas, por exemplo, por termoelétricas, e/ou também para minimizar as grandes faltas de energia. 
Com os resultados das matrizes, pode-se perceber que pelo motivo das $\mathrm{PCHs}$ estarem na mesma região e serem similares quanto a sua forma, basicamente verificaram-se os mesmos impactos com poucas alterações nos graus de significância. Dentreas diferenças percebidas pelas duas PCHs a que mais se destacou foi o comprimento do perímetro do canal que é consideravelmente maior para o caso da PCH Canhadão, o que consequentemente necessitou de uma quantidade maior de modificações no ambiente. Outros impactos que ficaram mais perceptíveis foram: o processo de desmatamento, o desvio do rio, as alterações na vazão de água a jusante no momento do enchimento do reservatório, amovimentação de solo e a explosão de rochas para durante a construção.

A possibilidade de ter conhecido a PCH Canhadão desde o início das obras, ou seja,ter visualizado as alterações geradas no meio foi de suma importância, pois, por exemplo, a PCH Tigre, quando iniciou esta pesquisa, já estava concluída, para tanto,não visualizou-se os impactos de forma mais detalhada, o que acarretou numa visão mais generalizada dos impactos, uma vez que esta pesquisadora não conhecia as áreas de estudo antes de iniciar a pesquisa. Este fato salienta a importância de analisar todas as fases de um empreendimento.

Conforme foi-se preenchendo e analisando ambas as matrizes, percebeu-se que o método RIAM, ao fragmentar os componentes do meio ambiente facilita no preenchimento, no entanto, em uma análise final verifica-se a necessidade de considerar o todo, pois um impacto intervém na formação ou ampliação de outro. Por exemplo, quando citado impactos em relaçãoa supressão de vegetação, com revolvimento do solo, gerando erosão tanto com esta atividade em específico quanto pela necessidade de cortes em solo para a implantação de partes da $\mathrm{PCH}$, acarretando consequentemente assoreamento do corpo hídrico.

Com os resultados obtidos através dos mapeamentos pode-se perceber que a região onde as $\mathrm{PCHs}$ em estudo foram implantadas, já vendo sendo antropizada a algum tempo, não percebendo alterações drásticas do ano de 2013 para 2017. As alterações verificadas no uso e ocupação do solo foram mais percebidas pelas atividades agrícolas desenvolvidas na região. 
Ao falar em mudanças no meio ambiente deve-se ter uma visão holística do assunto, uma vez que

\begin{abstract}
"um processo de mudanças não constitui nada de verdadeiramente novo; a mudança é intrínseca a vida. A velocidade com que ocorrem as mudanças é o que passa a ser cada vez mais a marca de nosso tempo. Esta velocidade de mudanças se acelera ao longo da história" (ALMEIDA e TERTULIANO, 2010, p. 168).
\end{abstract}

Além disto, uma das maiores preocupações é o crescimento constante da população mundial, pois todos desejam uma qualidade de vida melhor o que "potencializa algum tipo de colapso (como um esgotamento da capacidade regenerativa natural) nos sistemas de manutenção da vida que nos fornecem ar, água e solo para sobrevivência" (LIMA-E-SILVA, GUERRA e DUTRA, 2010, p. 217).

Neste sentido, cabe uma reflexão do quão necessário vem a ser novas obras para fomentar o crescimento de energia do país. Pois este colapso descrito também tem relação com o consumismo desenfreado, que por um lado necessita de matéria prima e energia para sua produção, e por outro lado gera quantidades exorbitantes de resíduos que infelizmente, em sua grande maioria, são destinados erroneamente, causando impactos ambientais e socioeconômicos desnecessários. Desnecessários ao ponto de vista de que primeiramente deve-se analisar a real necessidade de compra e, depois disto, o desperdício que gera-se na destinação inadequada dos resíduos, desperdiçando, grandes espaço para sua disposição, energia provindos de resíduos orgânicos, reutilização dos resíduos orgânicos na forma de compostagem por exemplo, e, resíduos recicláveis tanto na forma de reutilização quanto no próprio processo de reciclagem, o que consequentemente, necessita de menos matéria prima para a produção dos novos produtos.

No entanto, para Lima e Silva, Guerra e Dutra (2010), existem ações de impacto positivo, que objetivam o não esgotamento dos recursos naturais, como por exemplo, "a gestão responsável das unidades de conservação (parques e reservas), o reflorestamento de áreas degradadas [...] a gestão responsável do problema ambiental dentro das empresas" (p. 217-218). 
dos recursos naturais, nem degrade perigosamente os sistemas de manutenção da vida. A viabilidade deste projeto de sociedade ocorrerá mais rápida e facilmente se a sociedade como um todo [...] considerar seriamente os custos associados aos danos ambientais. Em outros termos, o planeta é finito, e na verdade está ficando pequeno para os seres humanos" (LIMA-E-SILVA, GUERRA e DUTRA, 2010, p. 218219).

Neste sentido, ao falar sobre impactos ambientais gerados por empreendimentos deve se relacionar com as medidas mitigadoras necessárias para que a atividade possa ser devidamente liberada, para o caso de barragens

\begin{abstract}
"mesmo que projetadas dentro das técnicas modernas e buscando provocar poucos impactos ambientais negativos, produz conflitos de objetivos, especialmente com a proteção e o aproveitamento dos recursos naturais. Por esta razão, na concepção e dimensionamento, na implantação e na operação de barragens, o empreendedor deve adotar uma série de medidas no sentido de evitar e/ou atenuar impactos ambientais negativos decorrentes desta atividade" (DIAS (coord), 2008).
\end{abstract}

Com isso, enfatiza-se a importância das PCHs em estudo efetivamente implantarem de forma responsável as medidas mitigadoras que se propuseram a realizar, aumentando e mantendo as práticas conservacionistas do local.

\title{
4 CONCLUSÕES
}

Com as matrizes de avaliação de impactos rápida - RIAM verificou-se que o método vem a acrescentar em um estudo de impacto ambiental, resumindo-o e facilitando aos leitores a compreensão dos resultados. Uma RIAM possibilita constatar de imediato os impactos considerados mais significativos tanto negativamente quando positivamente analisando suas particularidades nos diferentes meios em que a matriz possibilita fragmentar.

Pode-se identificar com os resultados das matrizes que os impactos significativamente negativos foram: a alteração da descarga a jusante em função do período de enchimento do reservatório e/ou de desvio permanente do rio, a inundação da vegetação com perda de patrimônio vegetal, o desmatamento dos locais das obras com prejuízo da produção florestal, o assoreamento do reservatório, os processos erosivos, a degradação das áreas utilizadas pela exploração de material de construção e pelas obras temporárias de construção civil (corte e movimentação 
de solo e rocha). E o impacto significativamente positivo foi: a rede viária, seja pelas benfeitorias ou pela abertura de novas vias.

Dentre os impactos diagnosticados, salienta-se a importância de serem realizadas as medidas mitigadoras e a manutenção daquele ambiente ainda mais vulnerável pelas alterações realizadas, destaca-se também a importância de uma equipe multidisciplinar trabalhando de forma conjunta em todas as fases.

Neste sentido, sendo aplicadas as medidas mitigadoras descritas nos estudos ambientais das PCHs de forma responsável e eficaz, auxiliando o meio a se equilibrar/regenerar novamente, tais impactos serão, em parte, minimizados e com o tempo, dependendo da significância, podem passar a serem vistos como parte integrante daquele meio. Portanto, pode-se dizer que no contexto em que se vive, de crescimento populacional, de aumento desenfreado em relação ao consumismo, de grande expansão da tecnologia, as PCHs, quando de forma responsável desde a escolha do local de implantação até sua manutenção na fase de operação ou se for o caso em uma desativação, são uma das formas mais sustentáveis que pode ser utilizada na região estudada.

Destaca-se que não foram estudadas outras formas de geração de energia e seus impactos, no entanto, prioriza-se a utilização de fontes renováveis e para a região as PCHs vêm como uma alternativa viável aproveitando-se dos recursos hídricos disponíveis. Além disto, no município em que as PCHs em estudo estão implantadas há outras PCHs em fase de planejamento e implantação, fato este percebido durante a pesquisa, neste sentido destaca-se que não foram considerados os impactos cumulativos causados por todos estes empreendimentos nesta pesquisa. Vale enfatizar que termos de referência, checklists e trabalhos de revisão bibliográfica servem para auxiliar no levantamento dos impactos e nas tomadas de decisões, mas não devem ser tomados como verdade única. Com isto, os mapas e as matrizes apresentados neste estudo serviram para auxiliar na compreensão dos impactos gerados pelas PCHs em estudo, mas não são de forma alguma um produto único, acabado e que não possa ser acrescido de outros métodos para a análise final. 


\section{AGRADECIMENTOS}

Os autores agradecem ao Programa de Pós-Graduação em Desenvolvimento Regional da UTFPR campus Pato Branco e aos responsáveis das PCHs pela autorização cedida para o estudo.

\section{REFERÊNCIAS}

A. MÜLLER - CONSULTORIA AMBIENTAL. Relatório de desempenho ambiental do empreendimento - RDAE. 2015. Curitiba-PR.

ANEEL - AGÊNCIA NACIONAL DE ENERGIA ELÉTRICA. Atlas de energia elétrica do Brasil - Parte II: fontes renováveis - Capítulo 3: Energia Hidráulica. 3. ed. - Brasília, 2008. Disponível em: http://www2.aneel.gov.br/arquivos/PDF/atlas3ed.pdf. Acesso em: 10 ago. 2016.

ANEEL - AGÊNCIA NACIONAL DE ENERGIA ELÉTRICA. Banco de Informações de Geração BIG. Capacidade de geração do estado do Paraná: Usinas do tipo PCH em operação. 2017. Disponível em:

http://www2.aneel.gov.br/aplicacoes/ResumoEstadual/GeracaoTipoFase.asp?tipo=5\&fase $=3 \& U F=P R: P A R A N \% C 1$. Acesso em: abril 2017.

ANEEL - AGÊNCIA NACIONAL DE ENERGIA ELÉTRICA. Banco de Informações de Geração BIG. Capacidade de geração do estado do Paraná: Usinas do tipo PCH em construção. 2017. Disponível em:

http://www2.aneel.gov.br/aplicacoes/ResumoEstadual/GeracaoTipoFase.asp?tipo=5\&fase $=2 \& U F=P R: P A R A N \% C 1$. Acesso em: abr. 2017.

ALMEIDA, Josimar R.; TERTULIANO, Marcos F. Diagnose dos sistemas ambientais: métodos e indicadores. In: Avaliação e perícia ambiental. 10. ed. Rio de Janeiro: Bertrand Brasil, 2010.

BASTOS, Anna C. S.; FREITAS, Antonio C. Agentes e processos de interferência, degradação e dano ambiental. In: Avaliação e perícia ambiental. 10. ed. Rio de Janeiro: Bertrand Brasil, 2010.

BLOG PCH CANHADÃO. Enchimento reservatório - PCH Canhadão. 2017. Disponível em: http://pchcanhadao.blogspot.com.br/. Acesso em: 17 ago. 2017.

BRASIL. Lei no 12.727, de 17 de outubro de 2012.Dispõe sobre a proteção da vegetação nativa. Disponível em: http://www.planalto.gov.br/ccivil_03/_ato20112014/2012/lei/l12727.htm. Acesso em: 31 dez. 2017. 
BRASIL. Resolução Normativa n 673, de 4 de agosto de 2015. Estabelece os requisitos e procedimentos para a obtenção de outorga de autorização para exploração de aproveitamento de potencial hidráulico com características de Pequena Central Hidrelétrica - PCH. Disponível em: http://www2.aneel.gov.br/cedoc/ren2015673.pdf. Acesso em: 13 jun. 2016.

DIAS, Marilza C. O. (coord.); PEREIRA, Mauri C. B.; DIAS, Pedro L. F.; VIRGILIO, Jair F. Manual dos impactos ambientais: orientações básicas sobre aspectos ambientais de atividades produtivas. 2. ed. Fortaleza: Banco do Nordeste, 2008.

ELETROBRÁS - CENTRAIS ELÉTRICAS BRASILEIRAS S.A. Capítulo 2 - Tipos de pequenas centrais hidrelétricas. In: Diretrizes para estudos e projetos de pequenas centrais hidrelétricas. Ministério das Minas e Energia. Janeiro de 2000. Disponível em: https://eletrobras.com/pt/AreasdeAtuacao/geracao/Diretrizes\%20para\%20Estudos\%20e\%2 OProjetos\%20de\%20Pequenas\%20Centrais\%20Hidrel\%C3\%A9tricas/cap2 pch.zip Acesso em: 16 jul. 2016.

FBF Construtora. PCH Canhadão 10 MW. Disponível em: http://fbfconstrutora.com.br/obras/. Acesso em: 15 nov. 2017.

FORTE - SOLUÇÕES AMBIENTAIS LTDA. PACUERA - Plano ambiental de conservação e uso do entorno do reservatório PCH Canhadão. 2016. Curitiba - PR.

FORTE - SOLUÇÕES AMBIENTAIS LTDA. Programa Ambiental de Geração de Mão de Obra Local PCH Canhadão. 2016. Curitiba - PR.

IJÄS, Asko; KUITUNEN, Markku T.; JALAVA, Kimmo. 2009. Developing the RIAM method (rapid impact assessment matrix) in the context of impact significance assessment. In: Environmental Impact Assessment Review.

IBGE - INSTITUTO BRASILEIRO DE GEOGRFIA E ESTATISTICA. Infográficos: evolução populacional e pirâmide etária. 2010. Disponível em:

https://ww2.ibge.gov.br/cidadesat/painel/populacao.php?lang=\&codmun=411440\&searc $\mathrm{h}=$ parana|mangueirinha|infograficos:-evolucao-populacional-e-piramide-etaria. Acesso em: 6 mar. 2017.

IBGE - INSTITUTO BRASILEIRO DE GEOGRAFIA E ESTATISTICA. IBGE divulga as estimativas populacionais dos municípios para 2017. Disponível em: https://agenciadenoticias.ibge.gov.br/agencia-noticias/2013-agencia-denoticias/releases/16131-ibge-divulga-as-estimativas-populacionais-dos-municipios-para2017.html. Acesso em: set. 2017.

IBGE - INSTITUTO BRASILEIRO DE GEOGRFIA E ESTATISTICA. População paranaense. 2017. Disponível em: https://cidades.ibge.gov.br/brasil/pr/panorama. Acesso em: set. 2017. 
LIMA-E-SILVA, Pedro P.; GUERRA, Antônio J. T.; DUTRA, Luiz E. D. Subsídios para avaliação econômica de impactos ambientais. In: Avaliação e perícia ambiental. 10. ed. Rio de Janeiro: Bertrand Brasil, 2010.

MARTINS, Leonardo M.; NETO, José M. M. Uso do método RIAM na avaliação de impactos ambientais de curtumes. In: REDE - Revista Eletrônica do PRODEMA Fortaleza, Brasil, v. 9, n. 2, p. 41-52 jul./dez. 2015. ISSN: 1982-5528.

PASTAKIA, Christopher M. R.; JENSEN, Arne. 1998. The rapid impact assessment matrix (RIAM) for EIA. In: Environmental ImpactAssessmentReview.

PCH CANHADÃO. Enchimento Reservatório - PCH Canhadão. 2017. Disponível em: http://pchcanhadao.blogspot.com.br/. Acesso em: 24 nov. 2017.

RECITECH AMBIENTAL. RAS da PCH Tigre. Disponível em: https://drive.google.com/file/d/OB_9jMh5TLkDbejcxUVI4UkFoNIE/view. Acesso em: 11 abr. 2016.

SÁNCHEZ, Luiz H. Avaliação de impacto ambiental: conceitos e métodos. 2. ed. São Paulo: Oficina de Textos, 2013.p. 5-24. 